
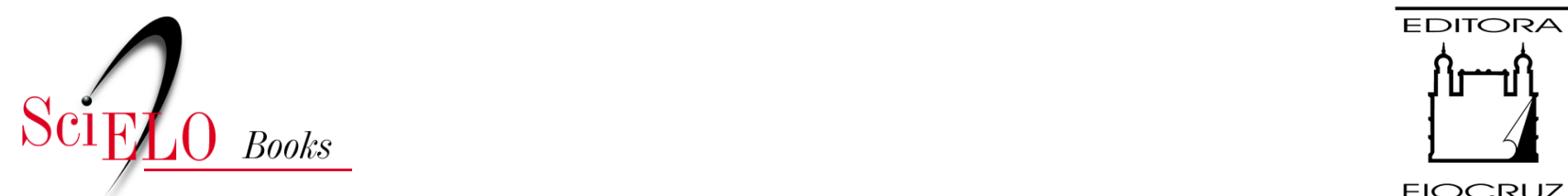

FIOCRUZ

\title{
1. Geração e trajetórias de inovação nos serviços de saúde
}

\author{
Laís Silveira Costa \\ Ligia Bahia
}

\section{SciELO Books / SciELO Livros / SciELO Libros}

COSTA, L.S., and BAHIA, L. Geração e trajetórias de inovação nos serviços de saúde. In: GADELHA, C.A.G., GADELHA, P., NORONHA, J.C., and PEREIRA, T.R., eds. Brasil Saúde Amanhã: complexo econômico-industrial da saúde [online]. Rio de Janeiro: Editora FIOCRUZ, 2017, pp. 23-60. ISBN: 978-65-5708-092-4. https://doi.org/10.7476/9786557080924.0003.

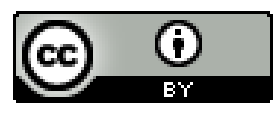

All the contents of this work, except where otherwise noted, is licensed under a Creative Commons Attribution 4.0 International license.

Todo o conteúdo deste trabalho, exceto quando houver ressalva, é publicado sob a licença Creative Commons Atribição 4.0.

Todo el contenido de esta obra, excepto donde se indique lo contrario, está bajo licencia de la licencia $\underline{\text { Creative }}$ Commons Reconocimento 4.0. 


\title{
GERAÇÃO E TRAJETÓRIAS DE INOVAÇÃO NOS SERVIÇOS DE SAÚDE
}

\author{
Laís Silveira Costa \\ Ligia Bahia
}

No Brasil, os desafios na área da saúde estão relacionados com as transformações que, ao longo das últimas seis décadas, têm ocorrido no sistema nacional de saúde; universalizar o acesso, reduzir custos e equilibrar a balança comercial emergiram como integrantes de um processo que desmercantilizou o acesso à saúde, mercantilizou a sua oferta e estimulou o surgimento de um conjunto de indústrias interligadas ao setor. A mudança no paradigma do acesso aos serviços de saúde foi iniciada com a formação de seguros ocupacionais e nacionais no século XX, que deram origem aos grandes sistemas públicos nacionais de saúde e fundamentaram a acepção da saúde como um direito, o de ter garantias para riscos considerados sociais.

No lado da oferta de serviços, o assalariamento dos profissionais da saúde ocorreu no início do século XX, por meio dos dispositivos da previdência social e dos serviços públicos, culminando na formação de uma densa trama institucional com unidades interligadas que desempenham, em determinados casos, simultaneamente, funções de prestação de serviços e comercialização de planos e seguros privados de saúde. Estes, por sua vez, desempenham a função de gerenciar a prestação de serviços e estão integrados aos circuitos de financeirização da economia. No que concerne à formação de grandes indústrias como as de base química e biotecnologia, mecânica, eletrônica e de materiais, que constituíram o denominado complexo industrial da saúde, muito dependente de inovações tecnológicas no setor, os desafios se referem à incipiência de uma base produtiva nacional e à geração de déficits crescentes na balança comercial em função da defasagem da tecnologia do setor em relação aos países produtores. No que diz respeito à demanda, envelhecimento da população e mudanças epidemiológicas e na estrutura ocupacional representam obstáculos estruturais para a universalização da saúde de acordo com os princípios constitucionais do Sistema Único de Saúde (SUS). Por sua vez, as alterações nos padrões de morbidade e mortalidade estão associadas com mudanças no acesso e na utilização de serviços voltadas para o atendimento de necessidades que incluem desde ações e cuidados preventivos até o uso de unidades de tratamento intensivo.

Essas tendências se projetam sobre uma trajetória do desenvolvimento no Brasil baseada, de 1930 até 1980, na substituição de importações, mas sem capacitação tecnológica endógena e com aumento da desigualdade social e regional, gerando uma assimetria que deixa de ser entre agricultura e indústria e passa a se caracterizar como clivagem entre atividades densas em conhecimento e atividades sem grande valor agregado. A adoção do receituário neoliberal, no fim do século XX, resultou na falta de investimentos indutores de inovação tecnológica na rede pública de laboratórios 
oficiais, que passaram a realizar atividades de formulação de medicamentos acabados, sem integração de produção e síntese das matérias-primas. A retomada do processo de indução do desenvolvimento social nos anos 2000 se baseia nos conceitos de subdesenvolvimento e de país em desenvolvimento como processo histórico, e não como etapas do percurso dos países desenvolvidos, e nas reflexões a respeito das defasagens entre os movimentos de criação e acumulação de capital na saúde e as políticas de universalização do direito à saúde. Balizadas por esses marcos, as políticas de investimento na saúde destinadas a conferir sustentabilidade, legitimidade e qualidade ao SUS se pautaram pela necessidade de elevar o peso dos segmentos produtivos de bens e serviços de saúde que atendem a demandas sociais e incorporam um grande potencial de inovação e de transformação nos novos paradigmas tecnológicos. Para Gadelha, Quental e Fialho (2003) o setor Saúde é um lócus fundamental de desenvolvimento econômico, uma vez que nele a inovação e a acumulação de capital geram oportunidades de investimento, emprego e renda. Segundo esses autores, o complexo econômicoindustrial da saúde (CEIS) é composto por um conjunto interligado de produção de bens e serviços em saúde, um grupo de atividades produtivas selecionadas que mantém relações intersetoriais de compra e venda de serviços.

Tendo como pano de fundo o panorama aqui delineado, procuramos articular a reflexão sobre os referenciais teóricos, a difusão e a trajetórias das investigações sobre mudanças nos serviços de saúde, em particular dos hospitais, com a situação atual e as perspectivas de expansão do conhecimento sobre processos inovadores e dos serviços envolvidos com atividades sistemáticas e permanentes de inovação.

\section{Inovação: usos e abusos do conceito}

As dificuldades que envolvem o conceito de inovação são sobejamente conhecidas. De acordo com reportagem publicada no Wall Street Journal, os diretores executivos das maiores empresas mencionam cada vez mais o termo em suas apresentações e conferências (Berman, 2013). Um levantamento do The Boston Consulting Group realizado em 2014 com 1.500 executivos solicitando a classificação da inovação em sua empresa em um espectro de 1 a 10 evidenciou que mais de dois terços a situaram no terço superior. No entanto, como o termo inovação tem sido utilizado para se referir a misturas de aromas em perfume, à elevação do teor de álcool em cerveja, a relatórios de créditos e a tatuagens temporárias para animais de estimação, questiona-se o seu significado inclusive no âmbito dos fóruns que reúnem executivos de grandes empresas.

Em função do consenso sobre a dependência de inovação para a sobrevivência das empresas, o significado de inovar muitas vezes pode se situar aquém das raízes etimológicas de innovatio e novus, que significam nova criação, algo novo, novidade. Uma acepção mais modesta, a que relaciona inovação com competitividade - manter o ritmo de disputa com os rivais - passou a ser aceita e amplamente veiculada. Assim, o conceito de competitividade, carregado pelo pressuposto de que alguns ganham e outros perdem, teria sido substituído pelo termo inovação, alusivo aos negócios que envolvam adaptação. Outra recente ampliação de significado da palavra inovação foi seu uso no sentido de otimização, especialmente como referência para a interação entre mudanças no processo de um produto final. 
De acordo com a Sociedade Portuguesa de Inovação (2004), a difusão do uso da palavra inovação no cotidiano das atividades empresariais é análoga à do conceito de qualidade nos anos 1990. As críticas ao uso abusivo do termo inovação se concentram em torno da indistinção entre inovar e apenas "ficar competitivo". As diferenças entre inovação e extensão de produto ou atualização seriam cruciais para questionar onde termina a sobrevivência e começa uma inovação real. Os que argumentam a favor de interpretações menos rígidas consideram que na dimensão pragmática, aquela envolvida com a criação, sustentabilidade e ampliação dos resultados das empresas, se um produto tem um desempenho compatível com tais necessidades, trata-se de algo que realiza inovação.

Apesar das divergências sobre os limites e as possibilidades da utilização da palavra inovação, o registro ampliado do conceito que conecta inovação com as finalidades das empresas tem sido adotado e legitimado por instâncias acadêmicas, especialmente da área dos cursos de administração para executivos. Há consenso sobre a desvinculação de inovação de um produto físico e questionamentos sobre as possibilidades de denominar de inovação novas formas de competição. Segundo Chintagunta (2014), existem quatro áreas de aplicação para o uso ampliado do conceito de inovação. A primeira se refere à precificação de um produto - por exemplo, aumento ou redução de valores de ingressos baseados na dinâmica do dia a dia da demanda. O argumento favorável a categorizar esse tipo de processo como inovação é a afirmação de que a tática para capitalizar diferenciais na preferência dos consumidores seria inovativa. A segunda área de aplicação diz respeito à marca, especialmente no que concerne às expectativas e aos resultados de lançamento de produtos que poderiam não ser rigorosamente considerados inovações, nem representam per se um significativo aumento da oferta, mas promovem a marca e todos os seus demais produtos. A terceira alternativa para o uso de inovação como nova categoria descritiva está afeta à extensão do uso de um produto que não introduz benefícios específicos para os consumidores, nem preenche lacunas nas necessidades da demanda, no entanto é empregado em outras atividades além da inicialmente proposta. A quarta se volta para a designação de benefícios para a sociedade que não representam inovações para as empresas, mas são direcionados para a base da pirâmide de renda - por exemplo, a oferta de calçados por um euro pela Adidas em Bangladesh, o sistema de baixo custo de filtragem da água da Unilever na Índia.

Obviamente, a transposição dessas interrogações e sugestões da ampliação do conceito de inovação para a saúde não é automática, e o alargamento do significado do conceito de inovação em um campo complexo de conhecimentos, saberes e práticas tem conotações singulares. No entanto, embora as definições clássicas de inovação como novo produto, nova técnica ou novo mercado não tenham sido abandonadas, a busca de definições abrangentes de inovação na saúde e em particular nos serviços de saúde tem sido uma marca dos estudos sobre o tema (Kaluzny et al., 1970). O pressuposto adotado para estabelecer marcos referenciais para o exame do tema inovação nos serviços de saúde é o de que os arranjos institucionais que compõem os sistemas de saúde são sociais e as análises sobre os diferentes tipos de inovação são socialmente determinadas (Kaluzny \& Veney, 1973). Tal enquadramento permite compreender as velozes mudanças tecnológicas na saúde vis-à-vis as tensões constitutivas entre qualidade e viabilidade financeira, bem como seus desdobramentos em termos de gestão organizacional e contextos regulatórios. 
Uma abordagem complementar aos estudos sobre inovação na saúde, aquela da inovação nos serviços de saúde, é a crítica ao denominado viés pró-inovativo. Greenhalgh (2013) identifica cinco vieses que perpassam a reflexão sobre inovação e saúde. O primeiro teria sido descrito pela primeira vez em 1960 pelo guru da inovação, Everett Rogers, que lançou uma classificação hierarquizada de pessoas e comportamentos: inovadores (o melhor tipo), seguido de early adopters, early majority, late majority e retardatário (como polo negativo). O segundo viés é denominado subjetivista e subjaz a parcela importante da retórica política sobre novas tecnologias, aquela que ressalta não resultados práticos, mas suposições otimistas sobre a contribuição que estas podem dar caso haja um desenvolvimento contínuo de pesquisas, se as tecnologias forem implementadas como anunciado e na ausência de barreiras de regulação ou técnicas-operacionais. O exemplo utilizado para demonstrar o problema é o da "adivinhação de um futuro próximo", no qual predominaria a calm computing ${ }^{1}$ e todas as tecnologias plug and play estariam disponíveis e isentas de falhas. $\mathrm{O}$ terceiro e o quarto estariam relacionados com o pressuposto segundo o qual o aumento da oferta de funções de determinadas tecnologias e de conectividade as torna, necessariamente, mais úteis e confiáveis. O último viés, concernente à intensificação dos estudos sobre robótica, resulta na exaltação acrítica das virtudes de substituição do humano por tecnologias que realizam atividades tão bem quanto este ou ainda melhor, inclusive capazes de suprir lacunas de relacionamento social.

A problematização das relações do setor industrial com os serviços, em sentido diverso daquele da valorização positiva da inovação na saúde, tem exposto os problemas advindos das investigações patrocinadas pelas empresas produtoras de medicamentos e equipamentos. Para Goldacre (2012), as evidências acumuladas ao longo das três últimas décadas são mais do que suficientes para demonstrar a existência de um fenômeno real e generalizado, que vincula a prescrição de medicamentos com a remuneração direta e indireta de médicos. A batalha para regular a produção e comercialização de medicamentos está longe de terminar, mas atingiu uma fase na qual se procura compreender e divulgar problemas e eventuais soluções e existe uma infraestrutura de governança das inovações, bem como um contra-ataque bem organizado da indústria de medicamentos para assegurar a expansão de seus negócios. A literatura sobre a inovação de outras tecnologias registra, por um lado, polêmicas sobre o ritmo de introdução que supera as evidências de efetividade e eficácia, e, por outro, a existência de barreiras à entrada de novos produtos impostas pelas grandes empresas e interesses de prestadores de serviços de saúde (Grennhalg et al., 2010; Shortell et al., 1996).

Estudiosos brasileiros consideram que as inovações na saúde potencializam a expansão do acesso e podem contribuir para a adequação do sistema às necessidades da população. Entretanto, os processos pretéritos e contemporâneos de geração de inovação em saúde não têm se pautado exclusivamente por demandas e condicionantes sanitários; ao contrário, frequentemente refletem uma trajetória de desenvolvimento que pode ser cativa de interesses de grupos restritos da sociedade (Costa et al., 2012). Daí a necessidade de levar em consideração a complexidade das distintas dimensões do

\footnotetext{
1 Conforme o dicionário Whatis.com, tecnologia calma é aquela reduz a excitação ou entusiasmo exagerado pela "sobrecarga de informações, e permite ao usuário selecionar as informações que devem permanecer no centro da sua atenção e as que são periféricas" (tradução nossa). A expressão foi cunhada em 1995 por Mark Weiser, chefe de tecnologia, e pelo diretor John Seeley Brown, da Xerox Palo Alto Research (Weiser \& Brown, 1995).
} 
CEIS para responder aos desafios de formular e implementar uma dinâmica inovativa virtuosa para a reestruturação dos serviços em saúde.

Assim, as tensões registradas pela literatura sobre o tema e as limitações para adequar reflexões sobre inovações e serviços de saúde realizadas em contextos de sistemas de saúde de países desenvolvidos ao sistema de saúde brasileiro que demarcam a área de estudos sobre inovações em serviços de saúde balizam o presente trabalho. O suposto que serve como fio condutor para relacionar as resenhas e sistematização das contribuições de estudiosos da inovação em serviços de saúde com o delineamento das perspectivas condizentes com as especificidades do sistema de saúde brasileiro é a necessidade de elaborar alternativas de caráter estratégico que potencializem programas táticos em curso.

\section{Políticas de Saúde, Sistemas, Serviços de Saúde e Inovação: referenciais teóricos}

Para Kaluzny (2007), os principais vetores que impactam as políticas de saúde são: as novas tecnologias; o envelhecimento da população; o aumento da diversidade étnica e cultural da população; mudanças na oferta e educação dos profissionais da saúde e a internacionalização dos serviços. Como as organizações de saúde têm sido caracterizadas como muito complexas e submetidas a velozes mudanças, a gestão dos serviços de saúde se tornou um fator relevante para a análise e a formulação de políticas públicas. Ratten (2012) considera a compreensão dos estilos gerenciais e iniciativas empreendedoras como uma chave interpretativa indispensável para os estudos sobre inovação na saúde. Assim, o conceito de inovação na saúde, especialmente a inovação nos serviços de saúde, inclui seus significados estruturados em termos de processos, organizações e produtos e desdobramentos conectados com a disrupção ou o incrementalismo das tecnologias, mas os remete à necessidade de ampliar a efetividade dos serviços de saúde.

Em seu trabalho sobre referencial teórico para inovação nos serviços de saúde, Kaluzny (1974) pressupõe que as dificuldades em eliminar as barreiras financeiras para o acesso desafiam os atuais sistemas de saúde a responder efetivamente às necessidades de saúde. Daí o crescente interesse pela inovação na saúde, uma vez que o ritmo acelerado das mudanças tecnológicas, a crescente especialização dos médicos e o rápido desenvolvimento de outras profissões da saúde, bem como o incremento na diferenciação e especialização dos serviços, impõem obstáculos à coordenação, e os sistemas de saúde tendem a aumentar despesas e produzem resultados com padrões de qualidade muito aquém dos desejados.

Ainda segundo Kaluzny (1974), o enquadramento para a análise das inovações nos serviços de saúde deve considerar três tipos de arranjo e formato institucional - público; filantrópico/comunitário e privado -, permeados por três características-chave, especialmente pertinentes à reflexão sobre inovação - autonomia da profissão médica e suas diversas especialidades; a ascendência de organizações formais; e a tendência da tecnologia de ponta e os valores a ela associados a influenciar o conjunto dos sistemas de saúde. Os tipos de arranjo institucional podem ser definidos pelo foco coletivo ou individual e pelo grau de unidade administrativa. As instituições públicas tendem 
a se direcionar mais ao coletivo do que aos indivíduos e têm alto grau de unidade administrativa; suas atividades estão sujeitas a controles administrativos relativamente rígidos. As organizações filantrópicas/comunitárias têm como foco principal de atenção os indivíduos e suas organizações, mantêm pouca relação entre si e não dispõem de um sistema integrado de controle administrativo; a estrutura interna desses órgãos se caracteriza pela dupla linha de autoridade, uma se concentrando na organização para o trabalho e outra se atendo ao desempenho do trabalho. O terceiro setor é constituído por profissionais e serviços de saúde que ofertam ações e cuidados de saúde em base individual. O indivíduo é o objeto exclusivo desse tipo de arranjo institucional, que tem como marca a limitada ingerência administrativa - ou até mesmo sua ausência - para o exercício da prática profissional. Portanto, a compreensão sobre a inovação nos sistemas de saúde necessariamente requer a análise sobre o potencial dos serviços de saúde (ou, mais especificamente, das organizações e dos profissionais da saúde) de se adaptar às mudanças e às alterações nas demandas. Portanto, o papel da inovação diz respeito à capacidade de adaptação dos diferentes elementos do sistema de saúde à emergência de novos problemas de saúde e às mudanças nas expectativas, nos valores e normas culturais e na esfera econômica e política.

No Quadro 1 estão sintetizados os elementos-chave do referencial teórico para a análise de inovação nos serviços de saúde elaborado por Kaluzny.

Quadro 1 - Referencial teórico de Kaluzny para a análise de inovações nos serviços de saúde: dimensões principais

\begin{tabular}{ll}
\hline Autonomia & A organização da prática médica é um elemento-chave das análises sobre inovação. \\
médica & Três aspectos da inserção e exercício da prática médica são particularmente relevantes: \\
& 1) a profissão é autônoma e a questão central não se reduz ao desempenho técnico \\
autônomo, mas contempla também a capacidade dos médicos para exigir autonomia & em âmbitos não técnicos envolvendo a organização dos serviços de saúde; 2) a \\
profissão pode ser vista como um amálgama de diversas especialidades médicas, com \\
diferentes objetivos e abordagens, mantidos sob um nome comum em determinado \\
ponto no tempo; esta conceituação contrasta com a visão tradicional da profissão \\
médica como uma comunidade estática e relativamente homogênea, cujos membros \\
compartilham valores, funções e interesses; 3) no nível da prática dos médicos, a \\
natureza da tarefa e o tipo de orientação psicológica necessária afetam a abordagem do \\
profissional na disseminação da inovação.
\end{tabular}


Quadro 1 - Referencial teórico de Kaluzny para a análise de inovações nos serviços de saúde: dimensões principais (cont.)

\begin{tabular}{|l|l|}
\hline 1) a maioria dos administradores não são médicos especialistas e as decisões \\
dentro dessas organizações exigem alto grau de participação (variável importante \\
na vinculação entre a decisão de implementar e a de adotar inovações); 2) os \\
administradores, embora tradicionalmente sejam médicos ou reverentes em relação \\
à profissão médica, estão sob crescente pressão para cumprir objetivos de alcançar \\
eficiência e responder a demandas sociais que conflitam com objetivos orientados \\
tecnicamente da comunidade médica. \\
O desenvolvimento de uma tecnologia extremamente sofisticada tem sido fundamental \\
para a ascensão de organizações formais nos sistemas de saúde. A diferenciação desta \\
tecnologia vis-à-vis seus objetivos e recursos tem implicações para a capacidade de \\
adaptação às novas demandas e necessidades, e sua receptividade a vários tipos de \\
pecnologia de \\
inovação pode ser identificada em duas dimensões: 1) à medida que a tecnologia se \\
torna mais sofisticada e baseada em corpus esotérico de conhecimento, as organizações \\
tendem a se proteger mediante o estabelecimento de uma dinâmica que envolve seus \\
próprios requisitos e processos tecnológicos, e essa dinâmica predispõe o sistema para \\
aceitar ou rejeitar certos tipos de inovação de forma totalmente independente das \\
necessidades de saúde; 2 ) a propensão para a aceitação de determinadas tecnologias \\
parte de ambos - provedores e consumidores de serviços de saúde - e se associa com \\
a inclinação para a ação diante de situações de elevada incerteza; tal predisposição \\
para a intervenção ativa, juntamente com a dinâmica do sistema que envolve os seus \\
próprios requisitos tecnológicos, favorece certos tipos de inovação.
\end{tabular}

Fonte: elaboração própria com base em Kaluzny, 1974.

A proposta de Kaluzny enfatiza a importância da compreensão da autonomia da prática médica e suas expressões objetivas como determinantes para o sucesso de qualquer mudança no sistema de saúde. A autora recupera a necessidade de encarar a profissão médica não como simplesmente um receptáculo que recebe ou se opõe à inovação. Sugere o exame da dinâmica das lutas de poder entre as várias disciplinas tradicionais e emergentes na medicina, afirmando que o fato de certas inovações serem mais bem aceitas do que outras evidencia utilidades adicionais àquelas da mera prestação de cuidados de saúde.

Uma tendência que tensiona a autonomia da prática médica é a crescente ascensão das instâncias administrativas e suas consequências tanto para a definição sobre qual seria a variável dependente adequada aos estudos sobre inovação na saúde quanto para a necessidade de observar a inclinação das organizações a desenvolver seus próprios requisitos tecnológicos. As organizações e os sistemas de saúde, por sua vez, têm mais receptividade a determinadas tecnologias que permitam fazer algo, isto é, que representem uma intervenção ativa em situações críticas - por exemplo, transplante de órgãos.

O quadro referencial que articula matricialmente os tipos de arranjo institucional com dimensões de níveis decisórios e tipos de tecnologia permite examinar inovações nos serviços de saúde, considerando os atributos de uma inovação em si. Serviços ou programas ou tecnologias implementados em hospitais são caracterizados principalmente por alto retorno em termos de qualidade dos serviços já ofertados pela organização, baixa taxa inicial de retorno de investimentos e reduzida atenção ou aprovação social. Nos demais estabelecimentos de saúde, as inovações se caracterizam por serem 
altamente divisíveis e terem custos relativamente baixos. A análise da sequência de adoção das inovações parece confirmar a existência de um padrão dependente do tipo de organização, e não apenas do tipo de inovação. Verificou-se que o padrão de inovação em hospitais pode ser compreendido como uma sequência unitária e não aleatória; constitui, portanto, uma escala de Guttman, ao passo que o padrão de adoção nos demais estabelecimentos de saúde segue um padrão diferente, não exibe escalabilidade (Kaluzny \& Veney, 1973).

Quadro 2 - Referencial teórico de Kaluzny para análise de inovações nos serviços de saúde: mensuração de inovação

MÉDICos
Variáveis
sociodemográficas
e de
personalidade,
situação
profissional e
características da
prática médica

ORGANIZAÇÕES DE SAÚDE

Variáveis relacionadas com características dos administradores

Variáveis relacionadas com características do pessoal da organização
As inovações são mais facilmente aceitas por aqueles que estão envolvidos em atividades especializadas, têm uma orientação racional e científica e são menos dogmáticos.

O nível de formação profissional e o grau de especialização estão associados com a propensão a aceitar inovações.

Estudos relacionam várias noções de orientação psicológica para a adoção da inovação.

Médicos mais diretamente interessados na medicina como ciência tendem a ser mais inovativos.

Outras variáveis sociodemográficas e de personalidade relativas à adoção de inovações são: idade mais jovem; a capacidade de nomear uma instituição de referência para a busca de informações e atualização de conhecimento; a proximidade da prática médica de uma escola médica.

Laços institucionais, contatos profissionais informais e relações de amizade contribuem para a difusão de inovações.

A inserção do médico individual no sistema de saúde, ou seja, o grau de integração com colegas e com a situação social dos pacientes, afeta o comportamento inovador em relação ao tipo de inovação.

O nível de formação profissional refletido na consciência de programas alternativos, grau de cosmopolitismo e situação social dos administradores ou gestores estão associados positivamente com a inovação organizacional. Contudo, há estudos que sugerem que quando o tamanho e a estrutura organizacional são controlados a importância das características do administrador tende a ser minimizada.

As variáveis contextuais e organizacionais são as principais responsáveis pela inovação organizacional. O tamanho da organização é a variável crítica que diferencia as organizações quanto ao investimento em ações e programas de alto risco versus programas de baixo risco. As organizações classificadas como inovadoras são caracterizadas pela baixa especificidade dos procedimentos ofertados, pela descentralização dos processos de tomada de decisão e pela alta complexidade. As organizações mais complexas e diversificadas são provavelmente mais inovadoras.

A complexidade (mensurada pelo número de tarefas especializadas dentro da organização) é o indicador estrutural mais importante da inovação organizacional.

Quatro fatores associados a processos internos de controle organizacional têm sido considerados nos estudos de inovação: visibilidade de consequências; padrões de comunicação; coordenação e estilos de liderança.

A dependência interorganizacional é uma variável importante para a inovação. As relações de poder entre organizações com recursos escassos podem ser inovativas porque a tomada de decisão no âmbito interorganizacional aumenta o poder de barganha de cada organização isoladamente. As organizações com mais programas conjuntos com outras instituições tendem a ser mais inovadoras. 
A tentativa de superar as lacunas para a compreensão e mensuração com base em modelos multiníveis é imprescindível para aprimorar as possibilidades de sucesso de políticas a serem implementadas. O modelo de Kaluzny busca articular diferentes abordagens explicativas em diferentes planos de análise.

Outra abordagem teórica para a análise da inovação nos serviços de saúde é o mapeamento dos diferentes agentes e interesses (stakeholders) envolvidos com os programas e projetos de desenvolvimento tecnológico que têm como pressuposto a necessidade de transpor duas barreiras à compreensão sobre sucessos e fracassos de políticas voltadas para o desenvolvimento e implementação de inovações: a falta de consenso sobre os construtos hipotéticos e a falta de consenso sobre a identificação e mensuração dos processos de inovação (Chaudoir, Dugan \& Barr, 2013; Velho, 2011, 2004).

Segundo Greenhalg (2012) podem ser identificados quatro discursos conflitantes, ao mesmo tempo que pervasivos, sobre inovações tecnológicas nos serviços de saúde. Os quatro discursos são referidos a uma concepção sobre inovações tecnológicas na saúde inscrita em uma comunidade de atores com valores e anseios, incluindo a indústria, o governo, organizações não governamentais, profissionais da saúde, pacientes e prestadores de serviços, pesquisadores e outros financiadores de serviços de saúde. A moldura para a apreensão e análise de feixes discursivos de agentes engajados nos processos inovativos é a acepção de que o lançamento de novas tecnologias requer: 1) interpretação - uma noção compartilhada daquilo que a tecnologia é e de como pode ser usada); 2) legitimação - uma lógica compartilhada sobre o que é a tecnologia e como deve ser adotada; 3) mobilização - estímulo e coordenação das partes interessadas para promover sua adoção e difusão.

O primeiro discurso é o denominado modernista, que considera os sistemas de saúde sobrecarregados, operando com capacidade máxima e em face de riscos de colapso, em consequência do aumento da longevidade da população e de demandas por novos bens e serviços, para expandir o acesso. A longevidade é encarada como um marcador positivo. As tecnologias são apresentadas como soluções racionais e de baixo custo para reduzir custos e gerar oportunidades de negócios. As tecnologias móveis e portáteis que assegurarão mais autonomia (reduzindo o contato entre pacientes e profissionais da saúde) são julgadas eticamente benignas. Alocações substanciais de recursos para construir as ligações intersetoriais e facilitar a pesquisa e o desenvolvimento foram justificados por meio de um discurso apoiado nas noções de aplicação de recursos e seu retorno e economias de escala. Os potenciais conflitos de interesses entre os agentes envolvidos com as inovações são reconhecidos e analisados. A mudança social prevista pelo discurso modernista é radical, de longo alcance e extensa alteração na base tecnológica: as novas tecnologias não serão utilizadas apenas para aprimorar as abordagens atuais dos problemas de saúde, mas sim para alterá-las (Greenhalg, 2012).

Um exemplo do discurso modernista pode ser encontrado no texto intitulado "Will disruptive innovations cure health care?", no qual se atribuem à corporação médica e aos hospitais vetos a inovações tecnológicas custo-efetivas (poderosas forças institucionais se opõem a alternativas que ameaçam sua subsistência). Segundo seus autores, tal como o telefone permitiu que as pessoas se comunicassem sem a necessidade de operadores de telégrafo, os avanços diagnósticos e terapêuticos requerem mudanças nos locais de intervenção, como ocorreu com os testes de glicose para pacientes de diabetes (Christensen, Bohmer \& Kenagy, 2000). 
O segundo tipo de discurso é o humanista; concebe tecnologias não necessariamente de forma negativa, desde que subsumidas à atuação de cidadãos em igualdade de condições na definição de suas necessidades e preferências. O discurso humanista difere do modernista nos seguintes aspectos: 1) não é centrado em tecnologias, mas nas experiências do processo saúde-doença e envelhecimento; 2) não se concentra em um futuro de alta tecnologia imaginado, mas na realidade do uso limitado de tecnologias; 3) enfatiza o significado simbólico de determinadas tecnologias como alarmes e tags que podem conotar intrusão, estigmatizacão e exposição à vigilância (ou seja, a medicalização do mundo da vida contribuiria para afirmar uma acepção de certas tecnologias como intrusas); 4) projeta as inovações tecnológicas como atividades participativas e interativas.

O terceiro feixe discursivo é o da economia política, cuja característica principal é a identificação e compreensão dos padrões tecnoeconômicos criados e perpetuados por interesses políticos e econômicos em torno das inovações. Um dos argumentos centrais do discurso da economia política é que os significados simbólicos conferidos às tecnologias estão subordinados a forças institucionais e à consciência (ou falta de consciência) de alternativas. Os discursos pertencentes à matriz da economia política questionam a narrativa da eficiência, isto é, a suposição de que as tecnologias aumentam necessariamente a eficiência e, consequentemente, representam alternativas de aumento de retornos e tendem a reduzir progressivamente os custos.

Adicionalmente, a reflexão sobre as inovações vinculada à matriz da economia política propõe que as tecnologias espelhem mudanças de valores sociais, que a saúde é um bem público e dever do Estado e que os valores neoliberais, segundo os quais a saúde das populações vulneráveis é um dever da sociedade, estimulam a adoção de alternativas meramente instrumentais (como, por exemplo, programas de inclusão digital) que não alteram a complexa determinação social do processo saúde-doença. Assim, uma solução tecnológica aparentemente simples, longe de ser uma força transformadora em direção a uma sociedade mais saudável, pode revelar formas injustas de controle social e aumento das desigualdades por meio da transferência de responsabilidade e carga de trabalho das instituições de saúde para as famílias.

A quarta matriz discursiva é a da mudança na gestão, e seus adeptos tendem a considerar as inovações tecnológicas como potencialmente benéficas, transformadoras e condutoras de redução de custos. Mas questionam o determinismo tecnológico do discurso modernista, ao enfatizar que as transformações exigem um grande volume de esforços adicionais e que as inovações tecnológicas são uma oportunidade para a mudança organizacional, e não o motor das transformações. Consequentemente, as crises e os problemas de saúde não podem ser atribuídos a lacunas tecnológicas, e sim à incompatibilidade entre as funcionalidades do sistema e práticas profissionais, ou à resistência, ou mesmo rejeição, por usuários finais de ações de saúde por razões que incluem preocupações com a relação paciente-profissional e a necessidade de redefinir as estruturas, os papéis e as hierarquias.

No Quadro 3 se expõem sinteticamente as relações entre agentes e as matrizes discursivas. De acordo com Greenhalgh (2012), a maioria dos discursos sobre inovação tecnológica se fundamenta na matriz modernista, seus elementos centrais são discerníveis e distintos uns dos outros, os pontos de contato são raros e não têm sido observadas mudanças nas narrativas no sentido não de informar, mas de propor diálogos interdisciplinares eficazes. 
Quadro 3 - Referencial teórico de Greenhalgh para a análise de inovações nos serviços de saúde: atores (agentes) sociais

Matrizes discursivas

$$
\text { e agentes }
$$

\section{MODERNISTA}

Executivos, empresários, políticos, instituições de pesquisa e pesquisadores das áreas biomédica, informática e business

\section{HUMANISTA}

Instituições acadêmicas da área de ciências sociais e determinadas organizações de pacientes

\section{ECONOMIA POLÍTICA}

Articulada (principal, mas não exclusivamente) por instituições e pesquisadores heterodoxos

\section{Posicionamentos, projetos, previsões}

A intervenção ocorrerá em fases cada mais precoces dos ciclos de vida e as tecnologias inclusive poderão estimular a escolha racional de estilos de vida mais saudáveis.

A infraestrutura de profissionais da saúde e de recursos físicos é encarada como tecnologias e estas são ubíquas, livres de erros e de fácil manejo.

Os cidadãos alfabetizados, incluídos digitalmente, qualificados tecnicamente e engajados socialmente terão pleno acesso a tecnologias que lhes permitirão acessar autonomamente de casas inteligentes (espaçosas, limpas, conectadas, seguras) soluções para problemas emocionais e monitoramento de doenças crônicas (Barlow et al., 2007).

Exemplos de inovações que representarão mudanças disruptivas nos sistemas de saúde: sensores ou outros equipamentos de monitoramento de sinais vitais a distância, a leitura dessas informações e a tomada de decisões, que poderá ser realizada em tempo real sem que o paciente precise recorrer a um prestador de serviços.

Cidadãos, pacientes, em particular idosos ou portadores de deficiência física ou cognitiva, são descritos como agentes ativos, engenhosos, que lutam para viver e dar sentido a suas vidas mediante cumprimento de obrigações sociais. As pessoas são os sujeitos, e não objetos de design e tecnologias, e por isso devem ser estimulados projetos de inovação participativos e qualitativos.

Equipes de saúde são propensas a falhas, a interoperabilidade do sistema de saúde é limitada e comportamentos de pacientes que se recusam a instalar, ligar ou utilizar as tecnologias (por exemplo, de telessaúde ou teleassistência) são entendidos como preservação das fronteiras entre o local de moradia e os serviços de saúde.

Determinadas tecnologias podem contribuir para aumentar o isolamento social porque afastam os pacientes de prestadores de serviços e familiares (permitiriam um afastamento de cheiros, necessidades emocionais, sofrimentos, conflitos interpessoais, fluidos corporais) e, portanto, dos contatos face a face entre pacientes e profissionais (Royal College of Nursing, 2013).

A inovação científica e tecnológica não é um exercício politicamente neutro na construção das atuais bases de conhecimento.

As atividades de pesquisa e marketing se conjugam e se cristalizam como cânones (narrativas que legitimam a necessidade de determinadas tecnologias) que integram simultaneamente postulados de verdade científica e inserção comercial; assim, o conhecimento gerado tem uma funcionalidade comercial implícita.

O atual impulso para controlar os custos crescentes dos sistemas de saúde pode estimular o incentivo a soluções tecnológicas apoiadas por poderosos interesses econômicos e comerciais de produtores e fornecedores de equipamentos, medicamentos, e a incerteza sobre a efetividade dessas inovações pode resultar em programas caros e inapropriados. 
Quadro 3 - Referencial teórico de Greenhalgh para a análise de inovações nos serviços de saúde: atores (agentes) sociais (cont.)

\begin{tabular}{|c|c|}
\hline $\begin{array}{c}\text { Matrizes discursivas } \\
\text { e agentes }\end{array}$ & Posicionamentos, projetos, previsões \\
\hline \multirow{5}{*}{$\begin{array}{l}\text { MUDANÇA NA GESTÃO } \\
\text { Consultorias de gestão }\end{array}$} & $\begin{array}{l}\text { Os formuladores de políticas de saúde, seduzidos pelo apelo racionalista da } \\
\text { tecnologia, podem confundir gestão das condições de saúde (isto é, o que é } \\
\text { necessário para viver bem, ainda que sendo portador de doença ou agravo } \\
\text { crônico) com o conjunto restrito de tarefas de gestão da doença (coleta } \\
\text { de dados biométricos, tais como pressão arterial, peso ou pico de fluxo } \\
\text { expiratório). } \\
\text { As previsões sobre a introdução de novas tecnologias consideram que as } \\
\text { inovações ocorrem em um ritmo lento, mediante negociações e competição de } \\
\text { interesses, e são limitadas por constrangimentos orçamentários, legislações, } \\
\text { culturas organizacionais e regulamentos profissionais. }\end{array}$ \\
\hline & $\begin{array}{l}\text { Uso intensivo de termos tais como complexidade e de metáforas orgânicas que } \\
\text { expressam uma perspectiva de sistema complexo adaptativo. Os sistemas de } \\
\text { saúde são descritos como um conjunto de partes e componentes para os quais } \\
\text { o principal desafio é essencialmente operacional: planejamento, gerenciamento } \\
\text { de projetos, clareza de papéis e responsabilidades integram abordagens } \\
\text { gerencialistas. }\end{array}$ \\
\hline & As inovações tecnológicas são constitutivas dos desafios gerenciais. \\
\hline & $\begin{array}{l}\text { Os passos para o desenvolvimento de serviços de saúde incluem: } \\
\text { 1) identificação de necessidades; 2) considerações sobre necessidades e } \\
\text { alternativas tecnológicas; } 3 \text { ) levantamento sobre os requisitos da força } \\
\text { de trabalho tais como formação de profissionais e gestão da inovação; } \\
\text { 4) avaliação do projeto; 5) implementação; 6) divulgação, difusão e } \\
\text { compartilhamento de boas práticas. }\end{array}$ \\
\hline & $\begin{array}{l}\text { Uma diferença fundamental entre o discurso da mudança na gestão e o } \\
\text { da economia política é que os conflitos são encarados como desafios de } \\
\text { gerenciamento; se forem seguidos os passos corretos, os efeitos em cadeia dos } \\
\text { problemas de relações desconectadas ou desalinhadas serão mitigados. }\end{array}$ \\
\hline
\end{tabular}

Fonte: elaboração própria com base em adaptação de Greenhalgh et al., 2012.

\section{As Trajetórias das Inovações nos Serviços de Saúde}

A trajetória da busca por inovação nos serviços de saúde é influenciada por quatro determinantes: o modo de busca por inovação; aspirações estratégicas; abundância de recursos; retorno do desempenho. O teste desse modelo em hospitais demonstrou a importância da persistência das atividades científicas em relação à busca de práticas inovativas (Greenhalgh et al., 2004; Chaudoir, Dugan \& Barr, 2013). As evidências revelam ainda a necessidade de um fluxo contínuo de novos produtos, processos e serviços em hospitais especializados que lhes assegurem participação na tomada de decisões estratégicas e a sustentação das atividades inovadoras. Há uma associação positiva entre maior folga financeira e a possibilidade de os hospitais efetuarem uma pesquisa inovadora contínua, baseada em uma infraestrutura científica sólida. 
Para Salge (2012), a adaptação organizacional depende fundamentalmente da busca contínua pela inovação, permitindo a reconfiguração das rotinas internas e ofertas externas, e valorizando seus recursos, novos produtos, serviços e processos. Em tempos de crescente dinamismo ambiental, a inovação e as pesquisas voltadas para a inovação são fundamentais tanto para gestores quanto para formuladores de políticas e pesquisadores. A persistência na busca por inovação tem importância tanto em termos teóricos quanto práticos, pois elucida a natureza dos processos de busca inovadores e também produz informações relevantes para os tomadores de decisão de programas e políticas voltados para a inovação. Ela gera, como proposto por Schumpeter $(1928,1984)$, um processo aleatório de destruição criativa, no qual empresários inovadores dilapidam a posição dos operadores históricos e se tornam eles próprios vítimas desse processo quando a geração seguinte de empresários de sucesso assume o comando. A pesquisa inovadora pode ser melhor entendida como um processo dependente da trajetória de acumulação criativa conduzida por agentes que obtêm vantagens mediante a acumulação sistemática de conhecimentos e de competências para gerar esforços inovadores. Os estudos sobre inovação na saúde focalizam quase exclusivamente os ambientes de produção. Por essa razão, a compreensão sobre a inovação nos serviços do setor público e privado ainda é muito limitada. No entanto, a inovação não pode ser encarada apenas como uma religião industrial, mas sim como atividade integrante de organizações de serviços, tanto do setor privado quanto do público (Damanpour \& Schneider, 2009).

Inovação é definida como "a geração, desenvolvimento e adaptação de novas ideias ou comportamentos. Uma inovação pode ser um novo produto ou serviço, um novo (...) processo (...), uma nova estrutura ou sistema administrativo, ou um novo plano ou programa pertencente a membros da organização" (Salge, 2012: 721, tradução nossa). Tal definição é suficientemente ampla para abarcar a atividade de inovação em suas múltiplas formas e manter seu significado específico. Uma vez que "o desenvolvimento de inovações é uma forma de pesquisa organizacional", usa-se o termo pesquisa inovadora para designar os atores envolvidos dentro das organizações no desenvolvimento de novos produtos, serviços e processos (Salge, 2012: 722).

Para Chen e Miller (2007), os investimentos financeiros e não financeiros em busca de inovação frequentemente são discricionários. Desse modo, os agentes decisórios têm considerável margem de manobra para moldar as atividades de busca inovadora em sua organização. Essa tendência influencia especialmente a intensidade e a direção das atividades da pesquisa inovadora. Consequentemente, os agentes decisórios se inclinam a adequar as atividades de busca inovadora às necessidades estratégicas e à dotação de recursos da respectiva organização. Entretanto, este é um processo inerentemente complexo, na medida em que os benefícios precisos e os custos da pesquisa inovadora costumam ter alto grau de incerteza e pressupõem horizontes de longo prazo. Além disso, os agentes tomadores de decisão têm restrições devido ao seu foco limitado e, portanto, não podem considerar todas as informações potencialmente relevantes para determinar o padrão de pesquisa inovadora mais adequado (Ocasio, 1997). Desse modo, aqueles que decidem tendem a usar métodos heurísticos simplificadores para orientar a busca de inovações em suas organizações.

A racionalidade dos processos de decisão é uma das chaves para explicar a variação interorganizacional nos esforços inovadores de novos produtos e mudanças organizacionais nos serviços de 
saúde (Salge, 2011). Portanto, tem-se recorrido à teoria comportamental da empresa para aprimorar a compreensão sobre as circunstâncias precisas em que os tomadores de decisão mantêm a motivação e a capacidade necessárias para sustentar as atividades de busca inovadora ao longo do tempo. E com base nesses pressupostos, da teoria comportamental, observa-se que os financiamentos a longo prazo para a pesquisa inovadora ajudam a reduzir a necessidade de os tomadores de decisão reavaliarem continuamente a intensidade e a direção de cada projeto. Uma vez que os compromissos de recursos permanentes para pesquisa inovadora receberam legitimidade interna, as negociações internas e os conflitos sobre a alocação de recursos têm menor probabilidade de acontecer (Chen \& Miller, 2007).

O processo de institucionalização da pesquisa costuma ser acompanhado pelo surgimento de rotinas de pesquisas específicas. As rotinas são padrões estáveis e repetidos de comportamento influenciados pelas regras e costumes específicos vigentes na organização (Edmondson, Bohmer \& Pisano, 2001). As rotinas, embora conotem estabilidade, são cada vez mais valorizadas por seu potencial transformador (Rerup \& Feldman, 2011). Isso é especialmente válido para rotinas que alimentam as atividades de adaptação organizacionais vitais, tais como inovação e aprendizagem organizacional. Assim, espera-se o desenvolvimento de rotinas para geração, assimilação e utilização de novos conhecimentos em serviços de saúde voltados para pesquisa inovadora. O desenvolvimento de rotinas e mecanismos de apoio que sustentam esforços de busca inovadores nas organizações fornece incentivos para a busca contínua e oportunidades de aprendizado cumulativo. Em particular, rotinas de pesquisa inovadoras tendem a se tornar mais eficazes quanto mais frequentemente são utilizadas. Em função do learning-by-doing e da "aprendizagem de aprender" (Stiglitz, 1987), a experiência de pesquisa aprimora as capacidades das organizações, facilitando, assim, as atividades de busca inovadora subsequentes (Malerba, Orsenigo \& Peretto, 1997). Da mesma forma, a pesquisa inovadora pode desencadear retornos financeiros positivos, gerando recursos adicionais para sustentar atividades inovadoras de busca das organizações. Portanto, institucionalização, rotinização, aprendizado cumulativo e retornos positivos promovem a estabilidade temporal das atividades voltadas para a inovação. De forma consistente com esses argumentos teóricos, a pesquisa empírica tem detectado altos níveis de persistência nos esforços de busca inovadores das organizações que se refletem nos gastos em pesquisa e desenvolvimento (P\&D).

Apesar de se esperar que, em geral, as buscas inovativas das organizações devam exibir forte estabilidade temporal, níveis de persistência podem diferir entre modos distintos de pesquisa para a inovação. Especificamente, esses níveis de persistência variam conforme a extensão em que as organizações são influenciadas e os seus graus de institucionalização, rotinização e aprendizado cumulativo. As atividades de pesquisa inovadora nos serviços de saúde podem ser classificadas em dois grandes grupamentos: 1) pesquisas baseadas em uma relativamente maior aproximação com a ciência e 2) inovações voltadas para a produção de serviços. Ou seja, em uma distinção entre ciência e pesquisas inovadoras baseadas na prática, ou, ainda, entre os modelos "ciência, tecnologia e inovação" e "fazer, usar e interagir". Esses modelos estariam localizados nos extremos opostos do espectro do gradiente das atividades de pesquisa inovadora no qual "inovar e aprender na prática diária se encontram no fim de um continuum de práticas inovadoras que se expandem até uma inovação radical cultivada em laboratórios de pesquisa no seu extremo oposto" (Brown \& Dugid, 1991: 53, tradução nossa). 
Pesquisas inovadoras fundamentadas na ciência normalmente requerem investimentos substanciais em recursos humanos e físicos. Estes incluem o recrutamento e treinamento de funcionários altamente qualificados, assim como o estabelecimento de laboratórios de P\&D com uma infraestrutura de suporte apropriada. Esses investimentos incorrem em custos altos irrecuperáveis a curto prazo e geram incentivos para manter pesquisas inovadoras ao longo do tempo (Sutton, 1991). O fato de as iniciativas de pesquisa inovadora fundamentadas na ciência serem costumeiramente organizadas como projetos formais de P\&D lhes confere visibilidade nos serviços de saúde e, consequentemente, maior probabilidade de atrair a atenção dos agentes tomadores de decisões, o que por sua vez leva a tentativas de rotinização e institucionalização. Similarmente, as rotinas que sustentam a pesquisa inovadora com base científica têm suas raízes na educação e no treinamento profissional dos funcionários. Além disso, a pesquisa inovadora fundamentada na ciência busca contribuir com o conhecimento técnico codificado, o que torna mais fácil o conhecimento cumulativo pela experiência, especialmente quando combinado com resultados de pesquisas anteriores.

Em contraste, a pesquisa inovadora fundamentada na prática ocorre como parte integral das atividades diárias de trabalho, e normalmente é abastecida pelos recursos já existentes. Portanto, requer menos investimentos em uma infraestrutura especializada e mecanismos de suporte, e não requer investimentos irrecuperáveis significativos. Dado que, na prática, está profundamente vinculada com as atividades de trabalho diárias, a pesquisa inovadora fundamentada muitas vezes não recebe a devida atenção dos agentes formadores de política, gerentes seniores e cotrabalhadores. Apesar de poder ser encontrada em qualquer lugar e de ocorrer em qualquer parte dos serviços de saúde, a pesquisa fundamentada na prática frequentemente se encontra invisível até mesmo para aqueles que fazem parte dela (Salge \& Vera, 2009). Isso cria um enorme desafio não apenas para os esforços empresariais de rotinização e institucionalização, mas também para o aprendizado cumulativo. Este se torna ainda mais difícil pelo fato de que a pesquisa inovadora fundamentada na prática depende fortemente do conhecimento pessoal, difícil de transmitir, e é menos passível de codificação e compartilhamento, tal como observado por Polanyi (Soares, 2012).

As pesquisas baseadas na ciência, dada a sua suscetibilidade à institucionalização, à rotinização e ao conhecimento cumulativo, tendem a se tornar mais estáveis ao longo do tempo do que as pesquisas baseadas na prática. Assim, as organizações de saúde tendem a reforçar suas atividades de pesquisa inovadora fundamentadas na ciência e não na prática, e a nelas persistir.

Embora os hospitais sejam uma fonte de importantes avanços no tratamento de doenças, o esforço de inovação em hospitais é subestimado, ou mesmo, em alguns casos, não reconhecido. Em particular, novos produtos, serviços e processos são desenvolvidos, não só no domínio da prática, mas também em uma série de outras funções hospitalares importantes, incluindo enfermagem, hotelaria, restauração, limpeza e administração. No Quadro 4, sobre a dinâmica da inovação em hospitais, procuramos sistematizar as alternativas de atividades inovadoras que ocorrem dentro dos hospitais e a gama de métodos ou hipóteses para estudá-las. Esta tipologia acentua a importância das atividades de busca inovadora com base na prática pertinentes à clínica e também de produtos não clínicos, serviços e processos (Djellal \& Gallouj, 2005). 
Quadro 4 - Métodos ou hipóteses para estudar as atividades inovadoras de pesquisa nos hospitais

\begin{tabular}{|c|c|c|c|c|}
\hline & Produtos & $\begin{array}{l}\text { Resultados/ } \\
\text { Otimização }\end{array}$ & $\begin{array}{c}\text { Processamento das } \\
\text { informações }\end{array}$ & $\begin{array}{l}\text { Provisão de } \\
\text { serviços }\end{array}$ \\
\hline $\begin{array}{l}\text { Abordagem } \\
\text { central }\end{array}$ & Políticas de saúde & $\begin{array}{l}\text { Profissionais da } \\
\text { saúde }\end{array}$ & $\begin{array}{l}\text { Administrador/ } \\
\text { Gestor }\end{array}$ & $\begin{array}{l}\text { Internações } \\
\text { hospitalares }\end{array}$ \\
\hline $\begin{array}{l}\text { Inspiração } \\
\text { disciplinar }\end{array}$ & Economia & Medicina & Administração & Sociologia \\
\hline $\begin{array}{l}\text { Objetivo principal } \\
\text { da pesquisa }\end{array}$ & $\begin{array}{l}\text { Maior eficiência } \\
\text { na produção de } \\
\text { cuidados à saúde }\end{array}$ & $\begin{array}{l}\text { Maior qualidade } \\
\text { dos resultados dos } \\
\text { serviços de saúde }\end{array}$ & $\begin{array}{l}\text { Melhor gestão da } \\
\text { informação clínica e } \\
\text { administrativa }\end{array}$ & $\begin{array}{l}\text { Melhor experiência } \\
\text { do paciente com os } \\
\text { cuidados como um } \\
\text { todo }\end{array}$ \\
\hline $\begin{array}{l}\text { Foco principal da } \\
\text { pesquisa }\end{array}$ & $\begin{array}{l}\text { Produtos clínicos e } \\
\text { processos inovativos }\end{array}$ & $\begin{array}{l}\text { Produtos clínicos } \\
\text { e inovações nos } \\
\text { serviços e processos }\end{array}$ & $\begin{array}{l}\text { Inovações } \\
\text { nos processos } \\
\text { administrativos } \\
\text { e estruturais e } \\
\text { inovações nos } \\
\text { produtos clínicos }\end{array}$ & $\begin{array}{l}\text { Serviços clínicos } \\
\text { e administrativos, } \\
\text { inovações de } \\
\text { processo e estrutura }\end{array}$ \\
\hline $\begin{array}{l}\text { Exemplos de } \\
\text { resultados de } \\
\text { pesquisas }\end{array}$ & $\begin{array}{l}\text { Novos } \\
\text { medicamentos, } \\
\text { tecnologias médicas } \\
\text { e processos de } \\
\text { tratamento }\end{array}$ & $\begin{array}{l}\text { Novos } \\
\text { medicamentos, } \\
\text { procedimentos } \\
\text { médicos, } \\
\text { tecnológicos e } \\
\text { processos de } \\
\text { tratamento }\end{array}$ & $\begin{array}{l}\text { Novos sistemas } \\
\text { de informação, } \\
\text { tecnologias médicas } \\
\text { e estruturas } \\
\text { organizacionais }\end{array}$ & $\begin{array}{l}\text { Novos processos } \\
\text { de tratamento, } \\
\text { procedimentos } \\
\text { clínicos, serviços } \\
\text { não médicos } \\
\text { e estruturas } \\
\text { organizacionais }\end{array}$ \\
\hline
\end{tabular}

Fonte: elaboração própria com base em Salge, 2011, 2012.

\section{A Inovação nos Serviços de Saúde: difusão das inovações}

As pesquisas sobre a difusão das inovações nos serviços de saúde evidenciam a importância dos contextos políticos, tecnológicos e ideológicos que envolvem a inovação e qualquer programa de disseminação, e em especial o valor social atribuído às inovações em diferentes sociedades. Há elevado grau de consenso sobre a importância da difusão das inovações à adequação de determinadas tecnologias e ideias para situações específicas em determinadas fases do desenvolvimento. Duas importantes conclusões derivadas dos estudos sobre a difusão de inovações são: 1) o significado de uma inovação para a agência que o apresenta pode ser muito diferente daquele assumido por aqueles que se pretende que a adotem, e 2) o sistema de inovação fit (relacionado à interação entre a inovação e o seu contexto potencial) pode se tornar uma construção válida e útil tanto ou quanto os atributos de inovação (Bourdenave, 1976).

De acordo com Greenhalgh e colaboradores (2004), das tradições relevantes para a difusão das inovações, quatro se referem às primeiras investigações significativas sobre a sua disseminação: 
1) Sociologia rural. Everett Rogers, em 1995, elaborou pioneiramente o conceito de difusão de inovações. Inovações foram definidas como ideias ou práticas percebidas como novas por profissionais (neste caso, agricultores). Difusão foi concebida como a disseminação de ideias entre os indivíduos, em grande parte, por imitação. As intervenções destinadas à difusão da inovação são atreladas à influência interpessoal dos líderes de opinião e agentes de mudança.

2) Sociologia médica. Conceitos e explicações teóricas similares aos da sociologia rural foram aplicados ao comportamento clínico dos médicos (principalmente no estudo realizado em 1966 por Coleman, Katz e Menzel sobre a propagação da prescrição de antibióticos recémintroduzidos); os primeiros estudos em sociologia médica definiram as bases para a rede de análise e estudo sistemático de "quem conhece quem" e "quem copia quem" e levaram à constatação de que indivíduos mais conectados a redes sociais têm grau de escolaridade mais elevado, status social superior e são adotantes precoces de inovações.

3) Estudos de comunicação. Inovações foram conceituadas como novas informações (muitas vezes como notícia) e disseminação foi concebida como a transmissão dessas informações por quaisquer meios de comunicação, inclusive a interpessoal; os estudos sobre difusão enfocaram medidas de velocidade e direção da transmissão da mensagem e estudaram possíveis impactos na alteração de variáveis, tais como o modelo de mensagem, o canal de comunicação (falada, escrita etc.) e a natureza da exposição.

4) Marketing. Inovações foram conceituadas como produtos ou serviços e a decisão de adoção encarada como uma análise racional (dos custos e benefícios); as pesquisas sobre difusão mensuraram o sucesso dos esforços para aumentar os benefícios ou reduzir os custos percebidos de uma inovação aos olhos de potenciais adotantes; importantes investigações nesta área desenvolveram modelos matemáticos para prever o comportamento da adoção de inovações.

As críticas às insuficiências e inconsistências dos primeiros estudos sobre difusão da inovação suscitaram o surgimento de outras áreas de reflexão sobre o tema, tais como:

1) Estudos sobre desenvolvimento. A difusão das inovações é explicitamente atribuída e ampliada ao contexto político, tecnológico e ideológico; qualquer programa de disseminação tem significado diferenciado, como inovações e valor social em diferentes sociedades; a difusão das inovações é tida como elemento central para a adequação de determinadas tecnologias e ideias para situações específicas em determinadas fases do desenvolvimento. Dois importantes princípios desta vertente são: a) o significado de uma inovação para a instituição/agência que a apresenta pode ser muito diferente daquela realizada pelos adotantes e b) o sistema de inovação fit é geralmente uma construção tão válida e útil quanto os atributos de inovação (muitas vezes, erroneamente assumidos como propriedades imutáveis da inovação em qualquer contexto) (Bourdenave, 1976).

2) Promoção da saúde. As inovações são definidas como boas ideias para estimular comportamentos saudáveis e estilos de vida, e a disseminação dessas inovações se expressa como o alcance e a absorção de programas de promoção da saúde em grupos-alvo definidos; as pesquisas sobre a promoção da saúde utilizam o marketing social, tomando a teoria de marketing como base conceitual. Mais recentemente, uma agenda mais radical baseada no enfoque de desenvolvimento surgiu na promoção da saúde, mantendo conexões com estudos de desenvolvimento, nos quais a transmissão unidirecional para o grupo-alvo foi 
substituída por vários modelos de parceria e de desenvolvimento comunitário (Potvin, Haddad \& Frohlich, 2001).

3) Medicina baseada em evidências. As inovações foram definidas como tecnologias e práticas de saúde sustentadas por evidências de pesquisa; a difusão da inovação, nesta vertente, é considerada um processo linear e técnico que ocorre no nível do indivíduo e, portanto, tem sido descrita com base na observação de mudanças no comportamento dos médicos, de acordo com diretrizes baseadas em evidências. Posteriormente, muitos pesquisadores da medicina baseada em evidências (talvez um pouco tardiamente) reconheceram que a implementação da maioria das diretrizes clínicas exige mudanças no sistema e, portanto, no nível organizacional (Grimshaw et al., 2004). Um desenvolvimento conceitual mais recente é a noção de que a base de evidências para determinadas tecnologias e práticas muitas vezes é ambígua e contestável e deve ser continuamente interpretada e reformulada de acordo com o contexto e as prioridades locais, um processo que muitas vezes envolve lutas de poder entre vários grupos profissionais (Ferlie et al., 2001).

\section{A Inovação nos Serviços de Saúde no Brasil}

A saúde revela-se um campo de alta intensidade de conhecimento e inovação, o qual incorpora e, principalmente, desenvolve tecnologias estratégicas que têm um impacto interdependente tanto no próprio Sistema Produtivo da Saúde quanto na dinamização do tecido econômico-produtivo. Apenas para citar alguns exemplos que estão longe de englobar as frentes sistêmicas existentes nas áreas de fronteira, podem-se destacar os seguintes que provocam alto impacto nos processos de transformação em curso e que articulam diversas áreas do Sistema de Inovação em Saúde: novas tecnologias médicas de alta complexidade que mobilizam todo o sistema de inovação (transplante, por exemplo); novas biotecnologias de fronteira; terapia celular na qual se desenha a fronteira entre os serviços assistenciais e a biotecnologia industrial; química orgânica avançada (química fina); tecnologia diagnóstica envolvendo plataformas tecnológicas para testes de diagnóstico de grande escala, com alta facilidade e precisão. Observa-se intenso aumento do esforço de P\&D em saúde no mundo, que cresce bem acima do gasto global com essas atividades e que talvez possa ser comparado apenas ao complexo de defesa. (Cassiolato et al., 2010: 4)

Por sua vez, o complexo industrial da saúde está inserido em determinado complexo político e institucional, condicionando e sendo condicionado pela dinâmica evolutiva do setor (Gadelha, Quental \& Fialho, 2003). Este último conta com quatro "forças" que influenciam o complexo industrial da saúde: instituições de ciência e tecnologia (C\&T); sociedade civil; população; Estado. Ao Estado compete atuar na mediação entre a oferta e a demanda de bens e serviços de saúde e responder aos desafios de conjugar a melhoria das condições de saúde com o desenvolvimento industrial e tecnológico na área (Gadelha, Quental \& Fialho, 2003). O Estado cumpre, portanto, papel fundamental na dinâmica do setor Saúde, mediante a realização de um conjunto amplo de atividades regulatórias que delimitam as estratégias dos agentes econômicos. Nesse contexto, o setor emerge como lócus fundamental para a geração e difusão da inovação no país e a saúde é concebida como integrante do sistema nacional de inovação e voltada para criar e estimular um padrão de desenvolvimento que aproxima a inovação do bem-estar. 
O aumento da expectativa de vida e a mudança nos padrões demográficos e epidemiológicos, a alteração no perfil de demanda em decorrência do aumento da prevalência das doenças crônicodegenerativas, a persistência e reemergência de determinadas doenças infecciosas e parasitárias e os altos índices de violência projetados ao longo de um vasto e heterogêneo território são desafios a que ainda não se respondeu adequadamente. Verifica-se clara inconsistência entre o gasto público em saúde, sua distribuição no Brasil e a conformação de um sistema universal, o que implica a necessidade simultânea tanto de aumento do financiamento público para os serviços quanto de fortalecimento da base produtiva nacional.

Em termos do CEIS [complexo econômico-industrial da saúde], como um todo, os elementos mais importantes que merecem ser destacados referem-se à crescente interação sistêmica no processo de inovação entre os segmentos produtivos. O esforço de tratamento e prevenção para um grupo de doença específico que tenha alta relevância - como câncer, por exemplo - mobiliza, a um só tempo, a busca de novos medicamentos, de prevenção com vacinas quando se evidencia sua relação com agentes infecciosos, a utilização de novos equipamentos eletrônicos para o tratamento e diagnóstico e a introdução de novas práticas assistenciais, em um processo de inovação que envolve, de forma interativa, os serviços médicos, diversos segmentos industriais e academia. (Cassiolato et al., 2010: 16)

As atividades que têm alto impacto nos processos de transformação, e articulam as diversas áreas do sistema de inovação e do CEIS são: 1) novas tecnologias médicas de alta complexidade, que mobilizam todo sistema de inovação (transplante, por exemplo); 2) novas biotecnologias de fronteira; 3) terapia celular, em que se desenha a fronteira entre serviços assistenciais e biotecnologia industrial; 4) química orgânica avançada; 5) tecnologia diagnóstica envolvendo plataformas tecnológicas para testes de diagnóstico de grande escala, com alta facilidade e precisão; 6) utilização intensiva de tecnologia da informação (TI) tanto nos serviços quanto nos equipamentos para diagnóstico e tratamento; 7) nanotecnologia (Cassiolato et al., 2010).

A despeito de seus segmentos produtivos serem relativamente estáveis, uma vez que a mudança tecnológica tende a ocorrer sem alteração profunda nos padrões competitivos vigentes, em termos internacionais o CEIS está passando por um processo de profundas transformações, entre as quais cabe destacar a busca por novas fontes de inovação diante do esgotamento das trajetórias em algumas áreas fundamentais (como ade medicamentos), a organização global das cadeias produtivas e das bases de P\&D, o enfrentamento e a arbitragem diante das condições políticas e sistêmicas de competitividade nacionais e locais, entre outros movimentos (Gadelha et al., 2012). O sistema produtivo da saúde torna-se um espaço competitivo mais orgânico, revelando a interdependência entre os distintos segmentos produtivos que convergem para o mesmo ambiente institucional e regulatório.

O Brasil, apesar de constituir um mercado mundial importante em todos os segmentos do CEIS, está em face do risco de ampliar o hiato em relação à fronteira tecnológica mundial, uma vez que a estrutura produtiva brasileira ainda se mostra bastante frágil, inclusive em termos de gestão corporativa, para enfrentar uma concorrência global mais acirrada e com atores de grande peso, atualmente também voltados para os mercados emergentes. Adicionalmente, os compromissos empresariais com atividades de P\&D envolvem baixa intensidade de conhecimento. A incorporação de inovações tecno- 
lógicas na saúde ocorre nas fases finais de lançamento de novos produtos e serviços, confundindo-se muitas vezes com as atividades de marketing, ou visando à superação das barreiras de regulação sanitária, ou adequação a estas (Cassiolato et al., 2010).

Os serviços são uma importante força motriz para a interação e a existência de uma dinâmica interdependente, constituindo-se simultaneamente como a atividade econômica que confere o caráter sistêmico à base produtiva e como a face mais visível do sistema de saúde. Os serviços de saúde constituem segmento de maior peso econômico do sistema e, portanto, com capacidade intrínseca tanto de gerar renda e emprego quanto de constituir o mercado final dos outros segmentos do complexo produtivo da saúde, além de ter uma participação decisiva - se bem que ainda pouco trabalhada - na dinâmica sistêmica de inovação (Costa et al., 2012).

A análise dos serviços de saúde no âmbito internacional evidencia a existência de um mercado com condicionantes específicos. A integração dos serviços e a competição em termos globais são distintas daquela que caracteriza a indústria de fármacos e medicamentos e de equipamentos médico-hospitalares, apesar das tendências recentes de ampliação dos investimentos internacionais nos hospitais e nas unidades de diagnóstico e terapia no país (Bahia, 2013).

As importantes mudanças nas características dos serviços de saúde que acompanham as transformações no conhecimento, nos saberes, não deslocaram por completo a centralidade dos hospitais nem no que se refere à concentração de profissionais e tecnologias mais especializados nem em sua importância financeira. As tabelas 1 e 2 sugerem uma estabilidade dos gastos com hospitais nos sistemas de saúde de países afluentes entre 2003 e 2013.

Tabela 1 - Gastos correntes com hospitais e gastos totais com saúde. Países selecionados - 2003 e 2013 (em US\$ milhões)

\begin{tabular}{lcccccc}
\hline \multirow{2}{*}{ Países } & \multicolumn{2}{c}{ Gastos com hospitais } & \multicolumn{2}{c}{ Gastos totais } & \multicolumn{2}{c}{$\%$} \\
& \multicolumn{1}{c}{2003} & 2013 & 2003 & 2013 & 2003 & 2013 \\
\cline { 2 - 7 } Canadá & $27.495,2$ & $48.682,9$ & $92.194,2$ & $158.296,2$ & 29,8 & 30,8 \\
França & $63.360,9$ & $112.007,9$ & $175.586,4$ & $282.188,0$ & 36,1 & 39,7 \\
Alemanha & $72.816,3$ & $117.191,0$ & $250.334,0$ & $396.922,7$ & 29,1 & 29,5 \\
Japão & $135.787,0$ & $218.334,6$ & $280.614,1$ & $528.508,7$ & 48,4 & 41,3 \\
EUA & $525.906,0$ & $933.916,0$ & $1.664 .482,9$ & $2.727 .394,9$ & 31,6 & 34,2 \\
\hline
\end{tabular}

Fonte: OECD. Stat, 2015, elaboração própria. Disponível em: <https://stats.oecd.org/Index. aspx? DataSetCode $=$ SHA $>$.

No Brasil, dados de aproximação das despesas com internações podem ser apreendidos em duas fontes: as internações remuneradas pelo SUS e aquelas remuneradas pelos planos de saúde. As informações contidas na Tabela 2, que representam apenas uma parte dos gastos com internação (os valores repassados pelo SUS, especialmente para o custeio corrente), mostram uma tendência de queda nas taxas de internação realizadas na rede SUS e pequena variação na proporção dos gastos com internações em relação às despesas públicas totais com saúde. 
Tabela 2 - Número de internações SUS, população, valor pago e despesas totais com saúde. Brasil - 2000-2011

\begin{tabular}{|l|c|c|c|c|c|c|}
\hline Ano & $\begin{array}{c}\text { n. de } \\
\text { nternações } \\
\text { SUS (a) }\end{array}$ & $\begin{array}{c}\text { População } \\
\text { brasileira (b) }\end{array}$ & $\begin{array}{c}\text { Taxa de } \\
\text { internação } \\
\text { em \% (a/b) }\end{array}$ & $\begin{array}{c}\text { Valor total das } \\
\text { internações } \\
\text { SUS (c) }\end{array}$ & $\begin{array}{c}\text { Despesas totais } \\
\text { com saúde* (d) }\end{array}$ & $\begin{array}{c}\text { Despesas com } \\
\text { internação em } \\
\text { \% (c/d) }\end{array}$ \\
\hline 2000 & 11.937 .323 & 171.279 .882 & 6,97 & 4.886 .848 .236 & 69.090 .000 .000 & 7,07 \\
\hline 2001 & 11.756 .354 & 173.808 .010 & 6,76 & 5.096 .155 .505 & 76.070 .000 .000 & 6,7 \\
\hline 2002 & 11.713 .749 & 176.303 .919 & 6,64 & 5.406 .391 .841 & 82.070 .000 .000 & 6,59 \\
\hline 2003 & 11.638 .194 & 178.741 .412 & 6,51 & 5.861 .712 .487 & 81.200 .000 .000 & 7,22 \\
\hline 2004 & 11.492 .883 & 181.105 .601 & 6,35 & 6.581 .213 .334 & 93.330 .000 .000 & 7,05 \\
\hline 2005 & 11.429 .133 & 183.383 .216 & 6,23 & 6.956 .764 .584 & 100.100 .000 .000 & 6,95 \\
\hline 2006 & 11.338 .039 & 185.564 .212 & 6,11 & 6.998 .043 .548 & 108.280 .000 .000 & 6,46 \\
\hline 2007 & 11.330 .096 & 187.641 .714 & 6,04 & 7.617 .769 .442 & 115.840 .000 .000 & 6,58 \\
\hline 2009 & 10.743 .603 & 189.612 .814 & 5,67 & 8.286 .055 .941 & 129.230 .000 .000 & 6,41 \\
\hline 2011 & 11.128 .809 & 191.480 .630 & 5,81 & 10.124 .918 .629 & 142.380 .000 .000 & 7,11 \\
\hline & 11.357 .965 & 193.252 .604 & 5,88 & 10.740 .754 .368 & 149.900 .000 .000 & 7,17 \\
\hline
\end{tabular}

* Valores deflacionados pelo Índice Nacional de Preços ao Consumidor Amplo (IPCA).

Fonte: elaboração própria com base em Datasus, 2014a, 2014b; IBGE, 2014; Subsecretaria de Planejamento e Orçamento/Ministério da Saúde (esfera federal) e Sistema de Informações sobre Orçamento Público em Saúde (Siops), 2014.

No que se refere aos planos e seguros de saúde, observa-se uma taxa de internação muito mais elevada do que a registrada para o SUS, ainda que se descontem do denominador do cálculo das internações na rede os clientes de planos privados e uma participação muito expressiva dos hospitais nas despesas totais das empresas de planos e seguros (Tabela 3). Em 2012 as despesas com hospitais representaram 42\% do total dos gastos assistenciais das empresas de planos e seguros no Brasil (ANS, 2014).

Tabela 3 - Taxa de internação de planos e seguros de saúde. Brasil - 2007-2011

\begin{tabular}{|c|c|}
\hline Ano & Taxa de internação \\
\hline 2007 & 13,3 \\
\hline 2008 & 13,4 \\
\hline 2008 & 13,0 \\
\hline 2009 & 13,7 \\
\hline 2010 & 14,1 \\
\hline 2011 & 13,9 \\
\hline
\end{tabular}

Fonte: ANS, 2014. 
Na Tabela 4, os dados sobre a oferta de serviços para planos privados de saúde referentes a dois períodos, 2010 e 2013, evidenciam o aumento do uso dos estabelecimentos de saúde e do número de leitos por clientelas privadas.

Tabela 4 - Vinculação de recursos físicos selecionados a planos privados de saúde. Brasil - 2010 e 2013

\begin{tabular}{lrrrrrr} 
& \multicolumn{3}{c}{2010} & & \multicolumn{2}{c}{2013} \\
& \multicolumn{1}{c}{ Total } & Não SUS & \% não SUS & Total & Não SUS & \% não SUS \\
\cline { 2 - 7 } Leitos & 462.760 & 125.979 & 27,22 & 452.454 & 131.029 & 28,96 \\
Hospitais gerais & 5.198 & 1.358 & 26,13 & 5.188 & 1.651 & 31,82 \\
Hospitais especializados & 1.200 & 401 & 33,42 & 1.094 & 433 & 39,58 \\
Unidades de diagnóstico & 16.305 & 6.095 & 37,38 & 20.017 & 8.757 & 43,75 \\
e terapia & & & & & &
\end{tabular}

Fonte: elaboração própria com base em ANS, 2007, 2013.

Esses dados sugerem a tendência à redução do número de leitos em função dos avanços científicos e tecnológicos que permitem que parte dos procedimentos, atualmente realizados exclusivamente no interior do hospital, passem a sê-lo em regime ambulatorial, conjugados a uma redivisão dos recursos assistenciais destinados às clientelas dos planos privados de saúde que possivelmente acentua a racionalização da assistência hospitalar no SUS.

Segundo Cassiolato e colaboradores (2010), na maioria dos países desenvolvidos os sistemas de saúde ainda são fortemente centrados no hospital e no médico. Serviços nucleados por pessoal de enfermagem são destinados a idosos ou focados em situações crônicas de saúde, em que o cuidado não dependa da prática médica, sugerindo que não há uma ruptura com o paradigma assistencial dominante, mas sim um processo intenso de transformação das trajetórias tecnológicas e a diferenciação do rumo e dos ritmos de progresso.

A racionalização das internações no SUS e o estímulo a determinados procedimentos hospitalares de maior complexidade e custo geram e reproduzem demandas por tecnologias diferenciadas agregadas ao leito de determinadas especialidades/áreas do conhecimento. Esse processo contribui para estimular nichos assistencial-comerciais em hospitais privados/filantrópicos e para segmentar a rede hospitalar do SUS, instituindo uma polarização entre um conjunto mais dinâmico de hospitais, que incorporam tecnologias, alcançam outras novas ou estabilizam escalas de produção economicamente mais sustentáveis, e os demais estabelecimentos. Em 2006, segundo dados do Cadastro Nacional de Estabelecimentos de Saúde (CNES), 293 hospitais no país vinculados à rede SUS tinham 201 leitos ou mais, representando apenas $4 \%$ da rede pública (incluindo os privados e particulares conveniados) e 39\% do total, ou seja, 2.659 hospitais tinham até 30 leitos, com menor dinamismo e limitada incorporação tecnológica.

Os dados individualizados do CNES referente ao ano de 2013 e a recursos físicos (hospitais gerais) evidenciam que dos 5.206 hospitais gerais, apenas 253 (4,8\%) contam com 201 ou mais leitos. Além disso, 13 desses hospitais de maior porte são instituições penitenciárias, psiquiátricas ou filantrópicas 
que não têm nenhum leito de terapia intensiva (Tabela 5). Esses hospitais estão majoritariamente vinculados ao SUS, como mostra a Tabela 4, embora se observe ligeira redução dos recursos físicos para o SUS em relação aos leitos de terapia intensiva.

Tabela 5 - Hospitais gerais com mais de 200 leitos. Brasil - 2013

\begin{tabular}{lcc} 
& Mais de 200 leitos & \% SUS \\
\cline { 2 - 3 } Número de leitos & 82.020 & 76,84 \\
Número de leitos SUS & 63.026 & \\
Número de leitos terapia intensiva & 10.511 & 70,09 \\
Número de leitos terapia intensiva SUS & 7.367 & \\
Relação leito terapia intensiva/leito & $12,8 \%$ & \\
\hline
\end{tabular}

Fonte: elaboração própria com base em Datasus \& CNES, 2013.

A distribuição geográfica dos hospitais gerais de maior porte é relativamente homogênea, embora se observe uma pequena concentração do número de hospitais de maior porte em São Paulo e no Rio de Janeiro e em alguns outros estados da federação, assim como a falta de unidade hospitalar no estado do Amapá (Tabela 6). O mesmo não ocorre em relação aos leitos disponíveis para o SUS. As diferenças entre as taxas de leitos disponíveis para o SUS por 1.000 habitantes variam desde aproximadamente 2 no Rio Grande do Sul e Rondônia até 1,2 e 1,3 em Sergipe e no Amazonas, sendo que São Paulo, que concentra o maior número de hospitais de maior porte, apresenta uma taxa menor do que a de várias unidades da federação, 1,4 (Tabela 7).

Tabela 6 - Distribuição dos hospitais gerais com mais de 200 leitos por unidade da federação. Brasil - 2013

\begin{tabular}{|l|c|c|c|c|}
\hline \multicolumn{1}{|c|}{ UF } & População* & & \multicolumn{2}{|c|}{$\begin{array}{c}\text { Hospitais } \\
\text { com mais de } \\
200 \text { leitos }\end{array}$} \\
\hline Rondônia & 1.590 .011 & 0,82 & 1 & 0,40 \\
\hline Acre & 758.786 & 0,39 & 1 & 0,40 \\
\hline Amazonas & 3.590 .985 & 1,85 & 1 & 0,40 \\
\hline Roraima & 469.524 & 0,24 & 1 & 0,40 \\
\hline Pará & 7.822 .205 & 4,03 & 5 & 1,98 \\
\hline Amapá & 698.602 & 0,36 & - & 0,00 \\
\hline Tocantins & 1.417 .694 & 0,73 & 2 & 0,79 \\
\hline Maranhão & 6.714 .314 & 3,46 & 5 & 1,98 \\
\hline Piauí & 3.160 .748 & 1,63 & 2 & 0,79 \\
\hline Ceará & 8.606 .005 & 4,44 & 10 & 3,95 \\
\hline Rio Grande do Norte & 3.228 .198 & 1,66 & 2 & 0,79 \\
\hline
\end{tabular}


Tabela 6 - Distribuição dos hospitais gerais com mais de 200 leitos por unidade da federação. Brasil - 2013 (cont.)

\begin{tabular}{|c|c|c|c|c|}
\hline UF & População* & $\%$ & $\begin{array}{l}\text { Hospitais } \\
\text { com mais de } \\
200 \text { leitos }\end{array}$ & $\%$ \\
\hline Paraíba & 3.815 .171 & 1,97 & 3 & 1,19 \\
\hline Pernambuco & 8.931 .028 & 4,60 & 9 & 3,56 \\
\hline Alagoas & 3.165 .472 & 1,63 & 4 & 1,58 \\
\hline Sergipe & 2.110 .867 & 1,09 & 2 & 0,79 \\
\hline Bahia & 14.175 .341 & 7,31 & 13 & 5,14 \\
\hline Minas Gerais & 19.855 .332 & 10,24 & 24 & 9,49 \\
\hline Espírito Santo & 3.578 .067 & 1,84 & 3 & 1,19 \\
\hline Rio de Janeiro & 1.6231 .365 & 8,37 & 30 & 11,86 \\
\hline São Paulo & 41.901 .219 & 21,60 & 76 & 30,04 \\
\hline Paraná & 10.577 .755 & 5,45 & 11 & 4,35 \\
\hline Santa Catarina & 6.383 .286 & 3,29 & 7 & 2,77 \\
\hline Rio Grande do Sul & 10.770 .603 & 5,55 & 25 & 9,88 \\
\hline Mato Grosso do Sul & 2.505 .088 & 1,29 & 1 & 0,40 \\
\hline Mato Grosso & 3.115 .336 & 1,61 & 4 & 1,58 \\
\hline Goiás & 6.154 .996 & 3,17 & 3 & 1,19 \\
\hline Distrito Federal & 2.648 .532 & 1,37 & 8 & 3,16 \\
\hline Total & 193.976 .530 & 100,00 & 253 & 100,00 \\
\hline
\end{tabular}

* População em 2012.

Fonte: elaboração própria com base em Datasus \& CNES, 2013 e Datasus, 2014a, 2014b. 
Tabela 7 - Número de leitos disponíveis para o SUS por UF. Brasil - 2014

\begin{tabular}{|c|c|c|c|}
\hline UF & Leitos SUS & População* & Leitos/1.000 hab. \\
\hline Rondônia & 3.257 & 1.590 .011 & 2,05 \\
\hline Acre & 1.198 & 758.786 & 1,58 \\
\hline Amazonas & 4.700 & 3.590 .985 & 1,31 \\
\hline Roraima & 777 & 469.524 & 1,65 \\
\hline Pará & 11.102 & 7.822 .205 & 1,42 \\
\hline Amapá & 979 & 698.602 & 1,40 \\
\hline Tocantins & 2.137 & 1.417 .694 & 1,51 \\
\hline Maranhão & 12.265 & 6.714 .314 & 1,83 \\
\hline Piauí & 6.957 & 3.160 .748 & 2,20 \\
\hline Ceará & 14.607 & 8.606 .005 & 1,70 \\
\hline Rio Grande do Norte & 6.344 & 3.228 .198 & 1,97 \\
\hline Paraíba & 7.733 & 3.815 .171 & 2,03 \\
\hline Pernambuco & 17.435 & 8.931 .028 & 1,95 \\
\hline Alagoas & 5.179 & 3.165 .472 & 1,64 \\
\hline Sergipe & 2.529 & 2.110 .867 & 1,20 \\
\hline Bahia & 24.940 & 14.175 .341 & 1,76 \\
\hline Minas Gerais & 29.950 & 19.855 .332 & 1,51 \\
\hline Espírito Santo & 6.009 & 3.578 .067 & 1,68 \\
\hline Rio de Janeiro & 26.643 & 16.231 .365 & 1,64 \\
\hline São Paulo & 59.272 & 41.901 .219 & 1,41 \\
\hline Paraná & 20.058 & 10.577 .755 & 1,90 \\
\hline Santa Catarina & 11.120 & 6.383 .286 & 1,74 \\
\hline Rio Grande do Sul & 21.811 & 10.770 .603 & 2,03 \\
\hline Mato Grosso do Sul & 3.772 & 2.505 .088 & 1,51 \\
\hline Mato Grosso & 5.093 & 3.115 .336 & 1,63 \\
\hline Goiás & 11.378 & 6.154 .996 & 1,85 \\
\hline Distrito Federal & 4.478 & 2.648 .532 & 1,69 \\
\hline Total & 321.723 & 193.976 .530 & 1,66 \\
\hline
\end{tabular}

* População em 2012.

Fonte: elaboração própria com base em Datasus \& CNES, 2013 e Datasus, 2014a. 
Essa polarização - especializações e tecnologias em um número pequeno de estabelecimentos e disponibilidade de recursos físicos (leitos e leitos de terapia intensiva) para o SUS (plausivelmente um traçador da importância do SUS para o financiamento de hospitais de maior porte) - ocorre em um contexto de crescimento do uso da maior parte da oferta de recursos hospitalares existentes pelos planos privados de saúde, como pode ser observado no Gráfico 1, e sugere uma divisão complexa da rede física de recursos para internação. Observa-se a concentração de recursos assistenciais de uso comum e a expansão, sem incremento da base física (por disponibilidade de recursos antes usados pela rede SUS), da oferta de leitos menos especializados para a clientela dos planos e seguros de saúde.

Gráfico 1 - Estabelecimentos de internação segundo tipo de pagador das internações. Brasil - 2006 a 2014 (março)

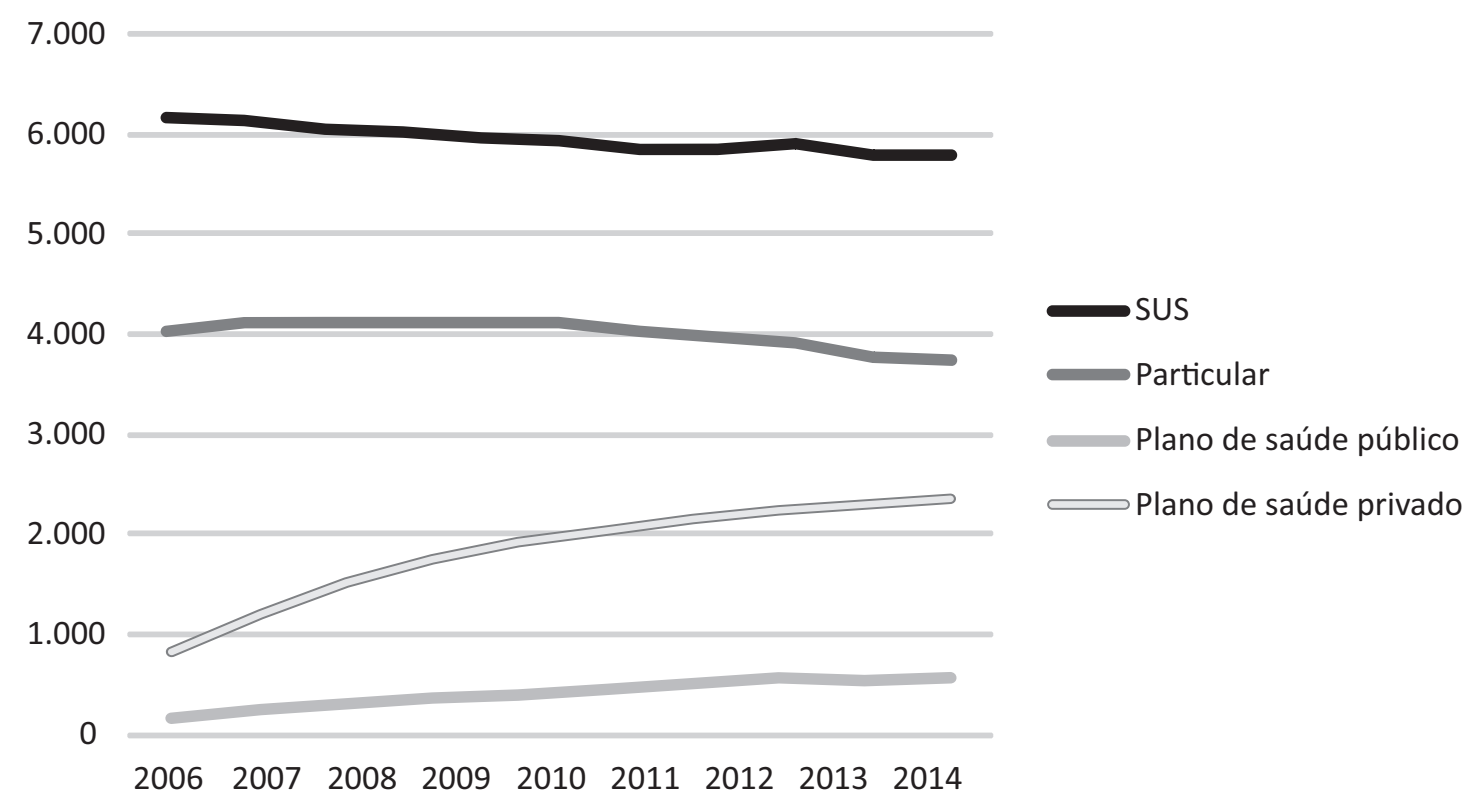

Fonte: ANS, 2014.

A tendência à concentração e especialização de recursos assistenciais também parece ocorrer no âmbito dos hospitais autoqualificados como de excelência vinculados à Associação Nacional de Hospitais Privados (Anaph). Dos 46 hospitais registrados em dezembro de 2013, apenas 26 tinham mais de 200 leitos, embora todos contassem com leitos de terapia intensiva. As tabelas 8 e 9 sugerem a existência no Brasil do fenômeno denominado nos EUA de "hospitais de alto e baixo preço", ainda que no interior de um estrato pretensamente homogêneo. Os dados confirmam os estudos internacionais sobre o porte dos hospitais e a capacidade de atrair recursos inclusive para inovação (White, Reschovsky \& Bond, 2014), e no caso brasileiro são fortemente sugestivos sobre a associação positiva entre a natureza filantrópica do estabelecimento e as receitas arrecadadas. 
Tabela 8 - Características dos hospitais vinculados à Associação Nacional de Hospitais Privados. Brasil - 2013

\begin{tabular}{lr}
\hline Número de hospitais & 46 \\
Número de leitos & 10.703 \\
Número de leitos de terapia intensiva & 2.433 \\
Relação leito terapia intensiva/leito & $23 \%$ \\
Faturamento em R\$ bilhões* & 8,5 \\
\hline * Referente a 34 hospitais que informaram o valor
\end{tabular}

* Referente a 34 hospitais que informaram o valor.

Fonte: elaboração própria com base em Anaph, 2013.

Tabela 9 - Faturamento por porte e natureza jurídico-institucional dos hospitais vinculados à Associação Nacional dos Hospitais Privados. Brasil - 2013

\begin{tabular}{|l|c|c|c|}
\hline & Número de hospitais & Número médio de leitos & $\begin{array}{c}\text { Faturamento } \\
\text { (em R\$ bilhões) }\end{array}$ \\
\hline Filantrópicos & 24 & 275 & 7,4 \\
\hline Com fins lucrativos & 11 & 144 & 1,1 \\
\hline
\end{tabular}

Fonte: elaboração própria com base em Anaph, 2013.

Esse padrão de polarização nas áreas pública e privada representa um desafio para o estudo e formulação de políticas sobre inovação e difusão de tecnologias nos serviços de saúde, uma vez que os circuitos dos processos de decisão relacionados com a inovação encontram-se, possivelmente, confinados a espaços e lógicas assistenciais não necessariamente voltados para mudanças na base produtiva e para a ampliação do acesso a serviços de saúde e do seu uso. Esse quadro torna-se ainda mais complexo em função dos processos de aquisição, fusões e financeirização e verticalização em empresas de planos e seguros de saúde em curso, ainda pouco estudados (Lima, 2014; Bahia, 2013).

Os estudos sobre inovação em serviços de saúde no Brasil ainda são escassos e não existem investigações ou esforços de mapeamento dos processos de criação ou incorporação de tecnologias no âmbito da rede assistencial. Dois elementos comuns à observação de analistas brasileiros são o protagonismo dos hospitais e as perspectivas do envolvimento dos setores baseados fortemente na ciência, o que pode ser exemplificado pela grande interação entre hospitais, indústria, universidade e Estado. O protagonismo dos hospitais na geração de inovação na saúde permite alterar a realidade da atenção hospitalar e do sistema assistencial como um todo em razão de seu impacto nas mudanças tanto nos próprios hospitais, tais como redução de leitos instalados, quanto nas práticas de atenção ambulatorial e disciplinar.

A inovação nos serviços hospitalares pode ser sistematizada em quatro grupos. No primeiro o hospital é considerado como uma empresa e, por conseguinte, visto com base na lógica de otimização do processo produtivo com uma expectativa de maior homogeneização vis-à-vis uma apropriada definição de tarifas. No segundo o hospital é visto como uma plataforma técnica e biofarmacológica, de forma que a evolução do sistema de saúde depende da biotecnologia e outras tecnologias. No terceiro os processos de inovação que ocorrem no hospital são vistos como causados pela introdução 
de novas tecnologias de informação e comunicação no seu interior. No quarto, a análise da inovação parte da consideração dos serviços e de suas relações no tratamento, separando as inovações tecnológicas (biotecnologia) das que ocorrem nos serviços (novos modelos e formatos de prestação de serviços) e das organizacionais (reorganizações administrativas, avaliação de qualidade do cuidado, desenvolvimento de protocolos), sociais e culturais. Para este, portanto, um modelo de análise dinâmica deve considerar essa complexidade de fatores (Barbosa \& Gadelha, 2012).

Para responder a desafios específicos do SUS é necessária a articulação sistêmica, e para isso as inovações são essenciais. Como observam Costa e colaboradores (2012), o uso de tecnologias como os diagnósticos remotos e a assistência domiciliar tem potencial para promover a diminuição relativa dos custos de prestação dos serviços, facilitar a integração dos diferentes níveis de atenção de um sistema de saúde e permitir o acompanhamento por meio de prontuários clínicos e atividades de atenção à saúde, mesmo que o profissional não se encontre na mesma localidade que o seu paciente. A incorporação de novas tecnologias também exerce impacto sobre a intensidade do uso dos leitos hospitalares, pois novos equipamentos, medicamentos e procedimentos qualificam e tornam mais resolutiva a atenção básica, o que reduz o tempo de internação e os riscos decorrentes. A integração da rede de atenção pode vir a se dar com o suporte da introdução de novas tecnologias, o que permitirá novas variações no formato da prestação de cuidados. O atendimento em casa e a incorporação de tecnologias que reduzem o tempo de internação hospitalar permitiriam que surgissem novos pontos de acesso e de interação qualificada entre o sistema e o paciente, especialmente nas regiões mais remotas.

Vecina e Malik (2007) ponderam sobre o potencial do estabelecimento de relações entre todos os agentes envolvidos na produção de bens e serviços de saúde, tal como tem ocorrido com a indústria farmacêutica para o desenvolvimento de protocolos assistenciais voltados para diagnósticos prioritários e em relação à indústria de equipamentos para desenvolver softwares adequados a seus utilizadores potenciais. Para os autores, ainda "faz falta, a percepção de que todos os envolvidos têm interesses comuns, integram a mesma cadeia de valor" (Vecina \& Malik, 2007: 835). Os comportamentos de comprador/fornecedor em que a vantagem de um é a perda do outro devem ser compreendidos e transformados em relações pautadas pelas necessidades de saúde e sustentabilidade do sistema de saúde. O fato de os hospitais do setor privado comercializarem medicamentos e materiais médicohospitalares, tornando-os mais um ponto de venda entre a produção e o uso pelo paciente, é um desafio incontornável.

\section{Inovação em Hospitais Brasileiros: a percepção de diretores de instituições selecionadas}

Responsáveis pelos processos decisórios de hospitais brasileiros envolvidos com atividades de pesquisa e ensino, os diretores consultados para fins de subsidiar uma reflexão sobre lacunas, desafios e perspectivas sobre inovação nos serviços de saúde traçaram um panorama bastante realista da situação atual dos esforços inovativos em suas instituições. As três instituições procuradas - dois hospitais especializados públicos (Hospital de Cardiologia de Laranjeiras, localizado no Rio de 
Janeiro, e Instituto Estadual do Câncer, em São Paulo) e um hospital geral filantrópico (Sírio Libanês, localizado em São Paulo) - desenvolvem atividades de ensino e pesquisa e mantêm projetos permanentes de pesquisa.

Os diretores desses estabelecimentos têm plena consciência da relevância dos processos inovativos e comungam a percepção de que suas instituições estão na fronteira do conhecimento de suas respectivas áreas de atuação. Os que atuam nas instituições públicas declararam conhecer de modo extenso e aprofundado as relações estabelecidas entre os distribuidores de material médico-hospitalar e o corpo clínico das instituições, bem como revelaram que o modus operandi para a incorporação de tecnologias é ainda dinamizado por demandas individuais de médicos que frequentam congressos e feiras hospitalares. O preconceito contra o produto nacional e as críticas à sua qualidade foram mencionados pelos três dirigentes. O diretor do hospital filantrópico, talvez por seu perfil profissional específico, mostrou maior conhecimento e formulou críticas, especialmente à Comissão Nacional de Ética em Pesquisa (Conep), sobre a dinâmica de aprovação de pesquisas clínicas. As três instituições estão planejando ou concluindo etapas de expansão de capacidade física instalada e de suas atividades de ensino e pesquisa no Brasil e na expectativa de atuação internacional. Como principal lacuna, a instituição pública não vinculada à universidade indicou a dificuldade de fixação de pesquisadores (sem carreira específica) e o hospital vinculado à Universidade de São Paulo as dificuldades burocráticas para conciliar a pesquisa com as regras da administração direta da Secretaria Estadual de Saúde (ver Apêndice).

Esse diálogo inicial e incipiente sinaliza que os estudos internacionais sobre inovação em serviços de saúde podem inspirar iniciativas para um mapeamento sistemático das inovações no Brasil considerando que as instituições abordadas de modo exploratório têm lideranças com aspirações estratégicas e dispõem de relativa abundância de recursos. Estas são características análogas às dos casos mencionados do Instituto do Câncer de São Paulo - no que se refere à necessária suplementação de valores da tabela SUS - e do Hospital Sírio Libanês - no tocante ao retorno em desempenho, seja financeiro, seja em termos de prestígio profissional. O diálogo com lideranças de instituições de serviços de saúde que desenvolvem atividades de ensino e pesquisa sugere que os hospitais públicos especializados que dependem de um fluxo contínuo de novos produtos, serviços e processos para atender às suas aspirações estratégicas estão mais bem posicionados para sustentar as atividades de busca baseadas em ciência do que os hospitais gerais. Mas essa afirmação não pode ser estendida aos hospitais privados.

\section{Lacunas no Conhecimento e na Formulação e Implementação de Políticas sobre Inovação nos Serviços de Saúde}

O Estado promoveu iniciativas para lidar com os empecilhos à inovação por meio de marco regulatório (Lei do Bem, Lei da Inovação, lei 12.349/2010, lei 12.401/2011, entre outras), do crescente apoio à inovação por parte dos produtores públicos e rede de laboratórios oficiais, do aumento substancial do orçamento e do estabelecimento de parcerias público-privadas para a transferência de tecnologia, entre outras. Essa agenda é essencial para a superação do descompasso 
entre a política de inovação e os interesses coletivos da saúde, e para desenvolvê-la é preciso estabelecer pautas de trabalho conjunto no qual se procure auscultar os agentes envolvidos na geração e incorporação de inovação, com o objetivo de diminuir as assimetrias de poder político e econômico dos atores do setor.

No que se refere à inovação de serviços de saúde, identificam-se seis tipos de lacuna: 1) número de serviços com atividades rotinizadas de pesquisa, ensino, C\&T e inovação reduzido, concentrado na região Sudeste e em hospitais especializados públicos e em alguns filantrópicos; 2) produção incipiente de conhecimentos sobre padrões e singularidades das inovações de serviços no Brasil; 3) processos decisórios sobre incorporação tecnológica fragmentados e desconectados dos esforços nacionais de aumento de fortalecimento da base produtiva nacional e do poder de compra do Estado; 4) inexistência de canais de conexão sistemática entre os serviços de saúde, os produtores e distribuidores de medicamentos, médicos e os órgãos governamentais responsáveis pelo registro, pela permissão e pela avaliação de tecnologias; 5) baixos padrões de remuneração dos serviços realizados especialmente nos hospitais privados induzindo à venda de medicamentos e materiais médico-hospitalares pelos hospitais; 6) informações incipientes de agentes decisórios de serviços de saúde sobre as políticas de saúde de C\&T. Além das inovações relacionadas com produtos, é essencial mapear as inovações decorrentes das práticas e aquelas diretamente conectadas com mudanças organizacionais. Daí a necessidade de identificar práticas inovadoras no âmbito da atenção primária à saúde e estimular e monitorar as tendências de automação, tanto em equipamentos biomédicos quanto em serviços, e destacar possibilidades reais e já regulamentadas legalmente para todo o manuseio de documentações médicas.

\section{Recomendações}

A reflexão e a formulação de políticas sobre inovações em serviços de saúde necessariamente terão que manter uma articulação permanente em função das tensões ideológicas e políticas que envolvem o tema e do alto grau de fragmentação e polarização tecnológica dos serviços de saúde no Brasil. Um caminho virtuoso em direção a tal articulação implica a busca de mobilização; a participação dos envolvidos; a atuação dos órgãos governamentais na criação, adequação e difusão das tecnologias, inclusive nos fóruns e no estabelecimento conjunto de regras para os mercados de distribuição e revenda de produtos que promovam a participação de todos agentes nos debates sobre as políticas de saúde. É também importante avançar na elaboração de estudos de mapeamento de inovações em serviços de saúde, conforme proposta a seguir:

1) Realizar um estudo linha de base (multinível, considerando as organizações e os profissionais da saúde e ainda as tecnologias baseadas na ciência e aquelas baseadas nas práticas) sobre inovação de serviços hospitalares, de diagnóstico e terapia e de atenção primária no Brasil, com a participação, em todas as etapas, dos agentes do setor.

2) Mapear indústrias e atividades de bem-estar, tais como academias da cidade e inovações arquitetônicas domésticas e telehealth.

3) Mapear a incorporação de tecnologias de registro eletrônico de informações assistenciais. 
4) Realizar reuniões das instituições que integram a rede de pesquisas clínicas para estabelecer uma agenda de apoio ao trabalho desenvolvido mediante identificação de nós críticos (carreiras para pesquisadores, relações com instituições financiadoras, convênios internacionais), bem como estimular por meio de editais a realização de pesquisas que envolvam redes regionais/locais de serviços coordenadas por instituições que já tenham rotinizado suas atividades de inovação.

5) Participar ativa e abertamente da organização e realização de eventos, tais como feiras hospitalares e exposições de produtores e distribuidores de medicamentos e equipamentos em congressos médicos, buscando por meio do conhecimento sobre a efetividade das tecnologias contribuir para o debate e a decisão sobre a sua incorporação.

6) Elaborar alternativas para a transição do modelo fee-for-service de pagamento vigente, especialmente nos hospitais privados, que estimula a revenda de materiais e medicamentos.

7) Orientar investimentos e esforços inovativos para a redução das desigualdades regionais considerando a difusão massiva (para o público especializado) das capacitações tecnológica e científica nos serviços de saúde.

8) Articular fóruns de debate de serviços de saúde, produtores e distribuidores de medicamentos e materiais médico-hospitalares com instituições e pesquisadores envolvidos com acreditação e qualidade e suas inter-relações com inovações.

Quadro 5 - Diretrizes para a elaboração de uma agenda sobre inovação nos serviços de saúde no Brasil

\begin{tabular}{|c|c|c|}
\hline Lacunas & Recomendações & Participantes/Perspectivas \\
\hline \multirow[t]{2}{*}{$\begin{array}{l}\text { Produção incipiente de } \\
\text { conhecimentos sobre padrões e } \\
\text { singularidades das inovações de } \\
\text { serviços no Brasil. }\end{array}$} & $\begin{array}{l}\text { Realizar um estudo linha de base } \\
\text { (multinível). } \\
\text { Mapear indústrias e atividades } \\
\text { de bem-estar. }\end{array}$ & $\begin{array}{l}\text { Pesquisadores da área de saúde } \\
\text { coletiva, diretores de serviços de } \\
\text { saúde, pesquisadores clínicos, } \\
\text { produtores e distribuidores, Ministério } \\
\text { da Saúde. }\end{array}$ \\
\hline & $\begin{array}{l}\text { Mapear a incorporação de } \\
\text { tecnologias de registro eletrônico } \\
\text { de informações assistenciais. }\end{array}$ & $\begin{array}{l}\text { Estudo linha de base sobre inovação } \\
\text { nos serviços de saúde. } \\
\text { Mapeamento de tecnologias de "bem- } \\
\text { estar" e de registro eletrônico de } \\
\text { informações assistenciais. }\end{array}$ \\
\hline $\begin{array}{l}\text { Número de serviços com } \\
\text { atividades de pesquisa, ensino, } \\
\text { C\&T e inovação reduzido e } \\
\text { concentrado. }\end{array}$ & $\begin{array}{l}\text { Reuniões da rede de pesquisas } \\
\text { clínicas e expansão de } \\
\text { articulações entre serviços } \\
\text { regionais/locais. }\end{array}$ & $\begin{array}{l}\text { Pesquisadores da área da saúde } \\
\text { pública, diretores e pesquisadores } \\
\text { clínicos, Ministério da Saúde, } \\
\text { secretarias de Saúde. }\end{array}$ \\
\hline Desigualdades regionais. & & $\begin{array}{l}\text { Expansão do número e tipo de serviços } \\
\text { de saúde com atividades de ensino, } \\
\text { pesquisa e inovação. }\end{array}$ \\
\hline
\end{tabular}


Quadro 5 - Diretrizes para a elaboração de uma agenda sobre inovação nos serviços de saúde no Brasil (cont.)

\section{Lacunas}

Processos decisórios sobre incorporação tecnológica fragmentados e desconectados.

Inexistência de canais de conexão sistemática entre os serviços de saúde e os produtores e distribuidores de medicamentos, médicos e órgãos governamentais.

Informações incipientes de decisores de serviços de saúde sobre as políticas de saúde de C\&T.

Padrões de remuneração dos serviços realizados especialmente nos hospitais privados induzem "revenda" de produtos.

\section{Recomendações}

Participar ativa e abertamente da organização e realização de eventos sobre difusão de tecnologias/debate sobre decisões estratégicas de incorporação de tecnologias.

Articular fóruns de debate de serviços de saúde, produtores e distribuidores de medicamentos e materiais médico-hospitalares.
Alternativas para a transição do modelo fee-for-service.
Participantes/Perspectivas

Ministério da Saúde, pesquisadores clínicos, pesquisadores de saúde pública, produtores distribuidores.

Política de difusão de tecnologias e inovação.

Processos de decisão sobre incorporação de tecnologias estratégicas compatíveis com a ampliação do acesso, uso e controle de custos.

Ministério da Saúde, ANS, empresas de planos e seguros, associações de hospitais, entidades médicas, produtores e distribuidores.

Pagamento prospectivo.

\section{Referências}

AGÊNCIA NACIONAL DE SAÚDE (ANS). Caderno de Informações de Saúde Suplementar, dez. 2007. Disponível em: <www.ans.gov.br/images/stories/Materiais_para_pesquisa/Perfil_setor/Caderno_informacao_saude suplementar/2007_mes12_caderno_informacao.pdf >. Acesso em: 8 nov. 2016.

AGÊNCIA NACIONAL DE SAÚDE (ANS). Caderno de Informações de Saúde Suplementar, dez. 2013. Disponível em: <www.ans.gov.br/images/stories/Materiais_para_pesquisa/Perfil_setor/Caderno_informacao_saude_ suplementar/2013_mes12_caderno_informacao.pdf >. Acesso em: 8 nov. 2016.

AGÊNCIA NACIONAL DE SAÚDE (ANS). Perfil do setor, dados e indicadores do setor, 2014. Disponível em: < www. ans.gov.br/materiais-para-pesquisas/perfil-do-setor/dados-e-indicadores-do-setor>. Acesso em: 1 maio 2014.

ASSOCIAÇÃO NACIONAL DE HOSPITAIS PRIVADOS (ANAPH). Panorama, out.-nov. 2013. Disponível em: <http://anahp.com.br/?gclid=CPT83YDFhdACFckIkQodYYwEpw>. Acesso em: 1 maio 2014.

BAHIA, L. Financeirização e restrição de coberturas: estratégias recentes de expansão das empresas de planos e seguros de saúde no Brasil. In: COHN, A. (Org.). Saúde, Cidadania e Desenvolvimento. Rio de Janeiro: Centro Internacional Celso Furtado, 2013.

BARBOSA, P. R. \& GADELHA, C. A. G. O papel dos hospitais na dinâmica de inovação em saúde. Revista de Saúde Pública, 46, supl.: 68-75, 2012.

BARLOW, J. et al. A systematic review of the benefits of home telecare for frail elderly people and those with long-term conditions. Journal of Telemedicine and Telecare, 13(4): 172-179, 2007. 
BERMAN, D. K. Is a peanut butter pop-tart an innovation? The Wall Street Journal. New York, Dec. 3, 2013. Disponível em: < http://online.wsj.com/news/articles/SB1000142405270230485480457923660141131050 2>. Acesso em: 1 maio 2014.

BOURDENAVE, J. D. Communication of agricultural innovations in Latin America: the need for new models. Communication Research, 3(2): 135-154, 1976.

BROWN, J. S. \& DUGID, P. Organizational learning and communities-of-practice: toward a unified view of working, learning, and innovation. Organization Science, 2(1): 40-57, 1991.

CASSIOLATO, J. E. et al. (Org.). Perspectivas do Investimento na Economia do Conhecimento. Rio de Janeiro, Campinas: Synergia, Unicamp, Instituto de Economia, 2010.

CHAUDOIR, S. R.; DUGAN, A. G. \& BARR, C. H. Measuring factors affecting implementation of health innovations: a systematic review of structural organizational provider patient and innovation level measures. Implementation Science, 8(22): 2-20, 2013.

CHEN, W. R. \& MILLER, K. D. Situational and institutional determinants of firms' R\&D search intensity. Strategic Management Journal, 28(4): 369-381, 2007.

CHINTAGUNTA, P. K. Don't knock “innovation”, create a framework for it. Chicago Booth. Chicago, 15 abr. 2014. Capital Ideas. Disponível em: <www.chicagobooth.edu/capideas/search?GSAq=innovation\&site=\%3C\%25 $\% 3 \mathrm{dBoothCollection}+\% 25 \% 3 \mathrm{E} \& \mathrm{client}=$ default_frontend\&output $=x m l \_$no_dtd\&proxystylesheet $=$defaul $>$. Acesso em: 1 maio 2014.

CHRISTENSEN, C. M.; BOHMER, R. \& KENAGY, J. Will disruptive innovations cure health care? Harvard Business Review, 78(5): 102-112, 2000.

COSTA, L. S. et al. A dinâmica inovativa para a reestruturação dos serviços de saúde. Revista de Saúde Pública, 46(1): 76-82, 2012.

DAMANPOUR, F. \& SCHNEIDER, M. Characteristics of innovation and innovation adoption in public organizations: assessing the role of managers. Journal of Public Administration Research and Theory, 19(3): 495-522, 2009.

DEPARTAMENTO DE INFORMÁTICA DO SUS (DATASUS). Assistência à Saúde. Internações Hospitalares, 2014a. Disponível em: <www2.datasus.gov.br/DATASUS/index.php?area=0202> . Acesso em: 1 maio 2014.

DEPARTAMENTO DE INFORMÁTICA DO SUS (DATASUS). Siops. Despesas, 2014b. Disponível em: <http:// portalsaude.saude.gov.br/images/pdf/2013/outubro/02/despesa-total-saude-021013.pdf $>$. Acesso em: 1 maio 2014.

DEPARTAMENTO DE INFORMÁTICA DO SUS (DATASUS) \& CADASTRO NACIONAL DE ESTABELECIMENTOS DE SAÚDE (CNES). CNES Estabelecimentos, 2013. Disponível em: <www2.datasus.gov.br/DATASUS/index. php?area $=0204>$. Acesso em: 1 maio 2014.

DJELLAL, F. \& GALLOUJ, F. Mapping innovation dynamics in hospitals. Research Policy, 34(6): 817-835, 2005.

EDMONDSON, A. C.; BOHMER, R. M. \& PISANO, G. Disrupted routines: team learning and new technology implementation in hospitals. Administrative Science Quarterly, 46(4): 685-716, 2001.

FERLIE, E. et al. Evidence-based medicine and organisational change: an overview of some recent qualitative research. In: ASHBURNER, L. (Ed.). Organisational Behaviour and Organisational Studies in Health Care: reflections on the future. Basingstoke: Palgrave, 2001.

GADELHA, C. A. G.; QUENTAL, C. \& FIALHO, B. C. Saúde e inovação: uma abordagem sistêmica das indústrias da saúde. Cadernos de Saúde Pública, 19(1): 47-59, 2003.

GADELHA, C. A. G. et al. A Dinâmica do Sistema Produtivo da Saúde: inovação e complexo econômico-industrial. Rio de Janeiro: Editora Fiocruz, 2012. 
GOLDACRE, B. Bad Pharma: how drug companies mislead doctors and harm patients. London: Fourth Estate, 2012.

GREENHALGH, T. Five biases of new technologies. British Journal of General Practice, 63(613): 425, 2013.

GREENHALGH, T. et al. Diffusion of innovations in service organizations: systematic review and considerations. Milbank Q, 82(4): 581-629, 2004.

GREENHALGH, T. et al. Adoption, non-adoption, and abandonment of a personal electronic health record: case study of Health Space. British Medical Journey, 341, 2010.

GREENHALGH, T. et al. The organization vision for telehealth and telecare: discourse analysis. BMJ Open, 2: 1-14, 2012.

GRIMSHAW, J. M. et al. Effectiveness and Efficiency of Guideline Dissemination and Implementation Strategies. Health Technology Assessment Report, 8(6): 1-72, 2004.

INSTITUTO BRASILEIRO DE GEOGRAFIA E ESTATÍSTICA (IBGE). População, projeção da população do Brasil por sexo e idade: 2000-2060, 2014. Disponível em: <www.ibge.gov.br/home/estatistica/populacao/ projecao_da_populacao/2013/default_tab.shtm>. Acesso em: 1 maio 2014.

KALUZNY, A. D. Innovation in health services: theoretical framework and review of research. Health Services Research, 9(2): 101-120, 1974.

KALUZNY, A. D. Vision and strategy for ubiquitous health care: the end of business as we know it. World Hospitals Health Service Journal, 43(4): 16-19, 2007.

KALUZNY, A. D. \& VENEY, J. E. Attributes of health services as factors in program implementation. Journal of Health and Social Behavior, 14(2): 124-133, 1973.

KALUZNY, A. D. et al. Diffusion of innovative health care services in the United States: a study in hospitals. Medical Care, 8(6):274, 1970.

LIMA, E. F. O caso do grupo D’Or. Projeto Grupos Econômicos no Sistema Brasileiro de Saúde. Relatório de pesquisa. Rio de Janeiro, 2014. (Mimeo.)

MALERBA, F.; ORSENIGO, L. \& PERETTO, P. Persistence of innovative activities, sectoral patterns of innovation and international technological specialization. International Journal of Industrial Organization, 15(6): 801-826, 1997.

OCASIO, W. Towards an attention-based view of the firm. Strategic Management Journal, 18, supl. 1: 187-206, 1997.

ORGANISATION FOR ECONOMIC CO-OPERATION AND DEVELOPMENT (OECD). Statistics. Health status. Disponível em: <http://stats.oecd.org/index.aspx?DataSetCode=HEALTH_STAT> . Acesso em: 1 abr. 2014.

POTVIN, L.; HADDAD, S. \& FROHLICH, K. L. Beyond process and outcome evaluation: a comprehensive approach for evaluating health promotion programmers. WHO Regional Publications, 92: 45-62, 2001.

RATTEN, V. A theoretical framework of entrepreneurship and innovation in healthcare organizations. International Journal of Social Entrepreneurship and Innovation, 1(3): 223-238, 2012.

RERUP, C. \& FELDMAN, M. S. Routines as a source of change in organizational schemata: the role of trial-anderror learning. Academy of Management Journal, 54(3): 577-610, 2011.

ROYAL COLLEGE OF NURSING. Telehealth and telecare. London, 2013. Disponível em: <www.rcn.org.uk/ development/practice/e-health/telehealth_and_telecare>. Acesso em: 1 maio 2014.

SALGE, T. O. A behavioral model of innovative search: evidence from public hospital services. Journal of Public Administration Research and Theory, 21(1): 181-210, 2011. 
SALGE, T. O. The temporal trajectories of innovative search: Insights from public hospital services: insights from public hospital services. Research Policy, 41(4): 720-733, 2012.

SALGE, T. O. \& VERA, A. Hospital innovativeness and organizational performance: evidence from English public acute care. Health Care Management Review, 34(1): 54-67, 2009.

SCHUMPETER, J. A. The instability of capitalism. Economic Journal, 38: 361-386, Sept. 1928.

SCHUMPETER, J. A. A Teoria do Desenvolvimento Econômico. 2. ed. São Paulo: Nova Cultura, 1984.

SHORTELL, S. M. et al. Remaking Health Care in America: building organized delivery systems. Michigan: JosseyBass, 1996.

SOARES, M. L. C. A Estrutura do Conhecimento Tácito em Polanyi: um paradigma pós-crítico para a epistemologia. Lisboa: Universidade Nova de Lisboa, 2012. Disponível em: <www.google.com/\#q=polanyi+dimens\%C3\%A 3o+tática >. Acesso em: 1 maio 2014.

SOCIEDADE PORTUGUESA DE INOVAÇÃO. O conceito de inovação,2004. Disponível em: <www.spi.pt/ documents/books/inovint/ippo/experimentar.manual/1.1/cap_apresentacao.htm >. Acesso em: 1 maio 2014.

STIGLITZ, J. E. Learning to learn: localized learning and technogical progress. In: DASGUPTA, P. \& STONEMAN, P. (Eds.). Economic Policy and Technological Performance. New York: Cambridge University Press, 1987.

SUBSECRETARIA DE PLANEJAMENTO E ORÇAMENTO/MINISTÉRIO DA SAÚDE (ESFERA FEDERAL) E SISTEMA DE INFORMAÇÕES SOBRE ORÇAMENTO PÚBLICO EM SAÚDE (SIOPS), 2014. Disponível em: <http:// portalsaude.saude.gov.br/index.php/o-ministerio/principal/siops > . Acesso em: 8 nov. 16.

SUTTON, J. Sunk Costs and Market Structure: price competition, advertising, and the evolution of concentration. Cambridge: MIT Press, 1991.

THE BOSTON CONSULTING GROUP. The 2014 health-care-services value creators report, 2014. Disponível em: $<$ www.bcgperspectives.com/content/articles/health_care_payers_providers_value_creation_strategy_finding sustainable_value_turbulent_market/?chapter $=2 \#$ ch̆ $a p>$. Acesso em: 18 maio $20 \overline{1} 4$.

VECINA, G. \& MALIK, A. Tendências na assistência hospitalar. Ciência \& Saúde Coletiva, 12(4): 825-839, 2007.

VELHO, L. Research capacity building for development: from old to new assumptions. Science, Technology and Society, 9(2): 172-207, 2004.

VELHO, L. Conceitos de ciência e a política científica, tecnológica e de inovação. Sociologias, 13(26): 128-153, 2011.

WEISER, M. \& BROWN, J. S. In design calm technology, 21 dez. 1995. Disponível em: <www.ubiq.com/ hypertext/weiser/calmtech/calmtech.htm>. Acesso em: 1 maio 2014.

WHITE, C.; RESCHOVSKY, J. D. \& BOND, A. M. Understanding differences between high-and-low price hospitals: implications for efforts to rein in costs. Health Affairs, 33(2): 324-331, 2014. 


\section{APÊNDICE}

\section{Contexto de Capacitação Tecnológica e Processos Inovativos de Hospitais Selecionados segundo Critérios de Participação em Pesquisas e Porte: potenciais e desafios destacados}

Os hospitais dispõem de profissionais qualificados, lideranças nas suas áreas de atuação e são muito bem equipados.

Os hospitais concentram profissionais com pós-graduação stricto sensu, mas alguns relatam necessitar de expertise específica ou não dispor de carreiras para pesquisadores. Poucas são as empresas responsáveis pelo suprimento da tecnologia incorporada, e destas as principais mencionadas foram GE, Siemens, PP/GE e Medtronic. Alguns hospitais contam com Núcleo de Avaliação Tecnológica (Nats), no entanto realizam procedimentos em suas áreas de atuação e especialização que ainda não integram os protocolos e diretrizes deste núcleo.

Destacaram-se entre as inovações tecnológicas: diagnósticos molecular/sequenciamento de DNA; ciclotron para radiofármacos; biobanco de tumores; vetores virais.

Um dos hospitais tem uma comissão orçamentária para materiais e insumos e outro um sistema de acompanhamento de tecnologia incorporada.

A percepção dos dirigentes dos hospitais é a de que "existe tudo que é necessário". Um deles afirmou que seu hospital não dispõe de equipamento PET-RM (que realiza, de forma integrada e simultânea, imagens de tomografia por emissão de pósitrons e de ressonância magnética) por ser "ainda muito caro" e registrou que "alguns testes são enviados para o exterior".

Os profissionais do hospital e gestores intermediários (chefes de serviços) tomam conhecimento das últimas inovações pela internet (artigos científicos) e em congressos. Um dos hospitais envia seus profissionais para congressos internacionais "sem participação de empresas no custeio". Outro, além dos incentivos à participação em eventos científicos, mantém profissionais "sendo preparados para inovação, em cursos no exterior".

No que se refere à origem (nacionalidade) da tecnologia utilizada, gerada ou incorporada foram elencadas as seguintes ponderações: a tecnologia complexa e recente utilizada é de origem internacional; a participação da indústria nacional se restringe a equipamentos de baixa complexidade, 
como bombas infusoras e monitores; "existe forte preconceito contra o produto nacional"; "não há muitos adeptos da tecnologia nacional no setor". No entanto, o preconceito se fundamenta em algum substrato real, na medida em que "a indústria nacional tem dificuldades para manter um nível elevado de qualidade".

Os hospitais selecionados realizam projetos/pesquisas sobre tecnologias nacionais.

As tendências tecnológicas registradas pelos serviços para 2030 foram: cirurgias minimamente invasivas guiadas por imagem; nanopartículas ativadas por ultrassonografia, terapias-alvo dirigidas, sequenciamento genético, marcadores tumorais, imagem molecular, paperless; pesquisa e protocolos de qualidade e segurança do paciente.

As pesquisas realizadas em um dos hospitais geraram duas patentes.

Sobre tendências de crescimento na prestação de serviços ambulatoriais, home care, cuidados domiciliares e outros, foram apontadas: expansão de serviços ambulatoriais mediante a construção e reforma para a criação de "grandes ambulatórios"; investimentos em internações de alta complexidade ("alta tecnologia").

Em relação às tecnologias de imagem, as expectativas de expansão registradas foram: imagens somatórios de tomografia computadorizada, PET e RM.

As principais pesquisas em curso se concentram nas áreas de oncologia, cardiopatia e ortopedia. As principais fontes citadas para o financiamento das pesquisas foram: indústrias; Fundação de Amparo à Pesquisa do Estado de São Paulo; Coordenação de Aperfeiçoamento de Pessoal de Nível Superior; Ministério da Saúde. 